\title{
Vibrational spectra and structure of the cis and trans conformers of methyl nitrite: an ab initio MO study
}

\author{
João Bosco P. da Silva ${ }^{a}$, Nivan B. da Costa ${ }^{a}$, Mozart N. Ramos ${ }^{a}$, Rui Fausto ${ }^{b, *}$ \\ ${ }^{a}$ Departamento de Quimica Fundamental, Universidade Federal de Pernambuco, 50740-250, Recife-PE, Brazil \\ 'Departamento de Química, Universidade de Coimbra, P-3049 Coimbra, Portugal
}

Received 22 May 1995; accepted 10 July 1995

\begin{abstract}
The vibrational and conformational properties exhibited by nethyl nitrite $\left(\mathrm{CH}_{3} \mathrm{ON}=\mathrm{O}\right)$ were studied by ab initio $\mathrm{MO}$ methods (HF-SCF and MP2) using both the 6-31G and 6-311G basis sets without or with the inclusion of diffuse and/or polarization functions. Fully optimized geometries, relative stabilities, dipole moments and harmonic force fields for both the cis and trans conformers of this molecule were determined and the results compared with available experimental data. In agreement with the experimental results, the calculations involving polarization functions at the MP2 level of theory indicate that the most stable conformer of methyl nitrite is the planar cis conformer, where the methyl group is eclipsing the $\mathrm{N}=\mathrm{O}$ bond, while the trans form was predicted to have a higher energy than this form by about $4 \mathrm{~kJ} \mathrm{~mol}^{-1}$. The conformational dependence of some relevant structural parameters was used to characterize the most important intramolecular interactions present in the studied conformers, and their calculated infrared spectra were used to review previous assignments of the experimentally observed bands for both the normal and deuterated $\left(\mathrm{CD}_{3} \mathrm{ON}=\mathrm{O}\right)$ species. Chemometrics methods (principal components and two-level factorial designing) were used both to analyze the effect of changing the basis set and level of theory used to perform the calculations, and to aid comparison between the experimental and calculated vibrational spectra.
\end{abstract}

\section{Introduction}

Alkyl nitrites exist as mixtures of cis and trans conformers which differ in the orientation of the alkyl group with respect to the nitrosyl moiety (Fig. 1). The smaller members of this family of molecules have been the subject of several experimental studies [1-19], and the most recent results consistently demonstrate that the cis conformer of methyl nitrite corresponds to the most stable form [815,17-19]. The gas-phase $\Delta H_{\text {trans-cis }}, \Delta S_{\text {trans-cis }}$ and $\Delta G_{\text {trans-cis }}$ obtained by ${ }^{1} \mathrm{H}$ NMR spectroscopy

\footnotetext{
* Corresponding author.
}

are $4.18 \mathrm{~kJ} \mathrm{~mol}^{-1}, 9.62 \mathrm{~J} \mathrm{~K}^{-1} \mathrm{~mol}^{-1}$, and $2.18 \mathrm{~kJ}$ $\mathrm{mol}^{-1}$, respectively [14]. The trans conformer was found to have a methyl top barrier to internal rotation much lower than that of the cis conformer $\left(120-790 \mathrm{~J} \mathrm{~mol}^{-1}\right.$ vs. $\left.8.74 \mathrm{~kJ} \mathrm{~mol}^{-1}[6,20]\right)$, and this has been correlated with its significantly higher entropy. Although the precise orientation of the methyl group in the trans conformer has still not been experimentally determined [6], the very small methyl internal rotation found for this form has been tentatively explained by assuming the existence of an intramolecular stabilizing interaction that lowers the energy of the rotational transition state $[12,20]$. Hartree-Fock SCF theoretical 


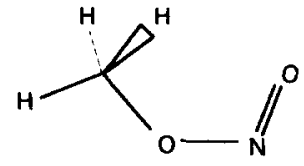

(I)

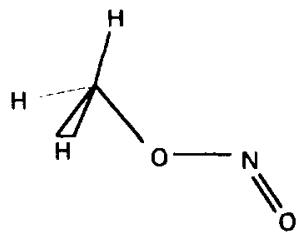

(II)

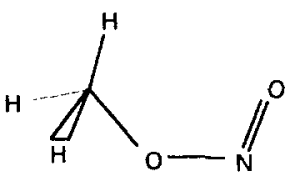

(III)

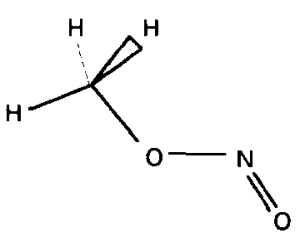

(IV)
Fig. 1. Relevant conformations of methyl nitrite. Forms I and II correspond to the stable conformers (cis and trans, respectively); forms III and IV are saddle points in the MP2 PES, being the rotational transition states to methyl internal rotation in cis and trans conformers, respectively.

studies of methyl nitrite, carried out using the popular split valence $4-21 \mathrm{G}$ basis set [21], have also been reported $[12,20]$. Very interestingly, although electron correlation has not been considered in these studies and a small basis set has been used, these theoretical results show reasonable agreement with experimental data, in particular with respect to the relative stability of the conformers and to the difference in the methyl top energy barrier in the two forms [12,20]. More recently, results of Hartree-Fock SCF $3-21 \mathrm{G}$ and $6-31 \mathrm{G}^{*}$ calculations have been reported $[18,19]$, which show a general agreement with the $4-21 \mathrm{G}$ results previously obtained. All these calculations predict the relative orientation of the methyl group in the trans conformer to be identical to that exhibited by the cis form (the staggered form, having an $\mathrm{H}_{\text {i.p. }}$ - $^{-}$ $\mathrm{C}-\mathrm{O}-\mathrm{N}$ dihedral angle equal to $180^{\circ}$; see forms I and IV in Fig. 1), and thus assume that the abovementioned intramolecular stabilizing interaction in the trans methyl internal rotation transition state is probably between the in-plane hydrogen and the nitrogen lone pair [20]. Despite the apparent success of the previously reported calculations, no systematic study of the effect of changing the basis set has been reported, nor has the importance of electron correlation been inspected. In turn, in order to confidently extend the theoretical studies to larger alkyl nitrites such analysis is absolutely necessary. This fact justifies the interest in performing additional structural studies on methyl nitrite by using a more systematic theoretical approach carried out at a higher level of theory.

The vibrational spectrum of methyl nitrite has also been studied by several authors under a series of different experimental conditions (gas phase $[1,4,9,11,13,17-19]$, pure liquid [18], solid [18], solution [4], noble-gas matrix [12,13,17], supersonic jet [8]). In addition, the infrared spectra of methyl$d_{3}$ nitrite in both the gaseous and solid phases $[13,18]$, and isolated in an argon matrix [13] have also been reported. However, a detailed vibrational

Table 1

Experimental and calculated relative energies $\left(\mathrm{kJ} \mathrm{mol}^{-1}\right)$ of the cis and trans conformers of methyl nitrite without $(\Delta E)$ or with $\left(\Delta E_{0}\right)$ zero-point vibrational energy corrections ${ }^{\mathrm{a}}$

\begin{tabular}{lrr}
\hline Method & $\Delta E$ & \multicolumn{1}{c}{$\Delta E_{0}$} \\
\hline Exp (gas phase ${ }^{\mathrm{l}} \mathrm{NMR}[14]$ ) & 5.44 & 4.18 \\
4-21G [12] & 14.63 & 12.27 \\
4-31G/4-21G [20] & 5.41 & 4.20 \\
$4-31 \mathrm{G}$ & 4.39 & 2.69 \\
$6-31 \mathrm{G}$ & 3.11 & 1.50 \\
$6-311 \mathrm{G}$ & 1.27 & -0.08 \\
$6-31++\mathrm{G}$ & -2.50 & -3.71 \\
$6-311++\mathrm{G}$ & -2.43 & -3.64 \\
$6-31 \mathrm{G}^{* *}$ & 6.23 & 4.23 \\
$6-311 \mathrm{G}^{* *}$ & 3.57 & 1.76 \\
$6-31++\mathrm{G}^{* *}$ & 2.01 & 0.28 \\
$6-311++\mathrm{G}^{* *}$ & -0.38 & -2.00 \\
MP2/6-31G & 4.59 & 3.47 \\
MP2/6-311G & 3.34 & 0.93 \\
MP2/6-31++G & -3.35 & -3.45 \\
MP2/6-311++G & -2.21 & -3.30 \\
MP2/6-31G** & 10.05 & 8.54 \\
MP2/6-311G** & 6.70 & 5.17 \\
MP2/6-31++G** & 4.62 & 3.19 \\
MP2/6-311++G** & 1.47 & 0.15 \\
\hline
\end{tabular}

a Calculated absolute energies ( $E$; hartrees, 1 hartrec $=$ $2625.5001 \mathrm{~kJ} \mathrm{~mol}^{-1}$ ) for the cis conformer are: HF-SCF, 4-21G $-243.074086,4-31 \mathrm{G}-243.2824507,6-31 \mathrm{G}-243.532090$, 6$311 \mathrm{G}-243.602485, \quad 6-31++\mathrm{G} \quad-243.540623,6-311++\mathrm{G}$ $-243.608032,6-31 G^{* *}-243.673408,6-311 G^{* *}-243.734277$, 6-31++G** $-243.680110,6-311++\mathrm{G}^{* *}-243.739301$; MP2 6$31 \mathrm{G} \quad-244.011746, \quad 6-311 \mathrm{G} \quad-244.113181,6-31++\mathrm{G}$ $-244.029407,6-311++\mathrm{G}-244.125848,6-31 \mathrm{G}^{* *}-244.349839$, $6-311 G^{* *} \quad-244.456100,6-31++G^{* *} \quad-244.365706, \quad 6-$ $311++G^{* *}-244.467430$. 
analysis has still not been performed on these molecules. Although the results of normal coordinate analyses have been presented previously $[9,13]$, such studies used the simplified valence force field approach (SVFF), thus neglecting several interaction force constants, which are chosen by a criterion that is necessarily not free of subjectivity. In addition, in these studies, both the diagonal and interaction force constants were assumed to be equal in both conformers, and the initial values to be used in the adjustment process of the force constants were transferred from different molecules [9,13]. Indeed, all these assumptions and approaches may nowadays be considered as rude approaches, thus justifying the interest in performing a more precise and reliable vibrational analysis on the considered molecule. The single study previously undertaken, where an ab initio calculation of the force constants was carried out [18], used the Hartree-Fock 3-21G wavefunction and the fixed scaled force field approach. However, as will become clear in the present article, the Hartree-Fock level of theory is not accurate enough to enable a reliable prediction of the vibrational spectra of the considered molecules, since both HF-SCF calculated wavenumbers and, in particular, intensities do not agree satisfactorily with the experimental data.

In this article, the vibrational and conformational properties of methyl nitrite are studied by means of a systematic series of ab initio HF-SCF and MP2 calculations using both the 6-31G and 6$311 \mathrm{G}$ basis sets without or with the inclusion of diffuse and/or polarization functions. This set of calculations, representing all possible combinations of four factors, is analyzed using the twolevel factorial design (TLFD) multivariate chemometrics technique [22] in order to access both the basis set dependence and the importance of electron correlation for the calculated conformational energies. Fully optimized geometries, relative stabilities, dipole moments and vibrational spectra for both cis and trans conformers of this molecule are reported, and the results compared with the available experimental data. Chemometrics methods were also used to analyze the

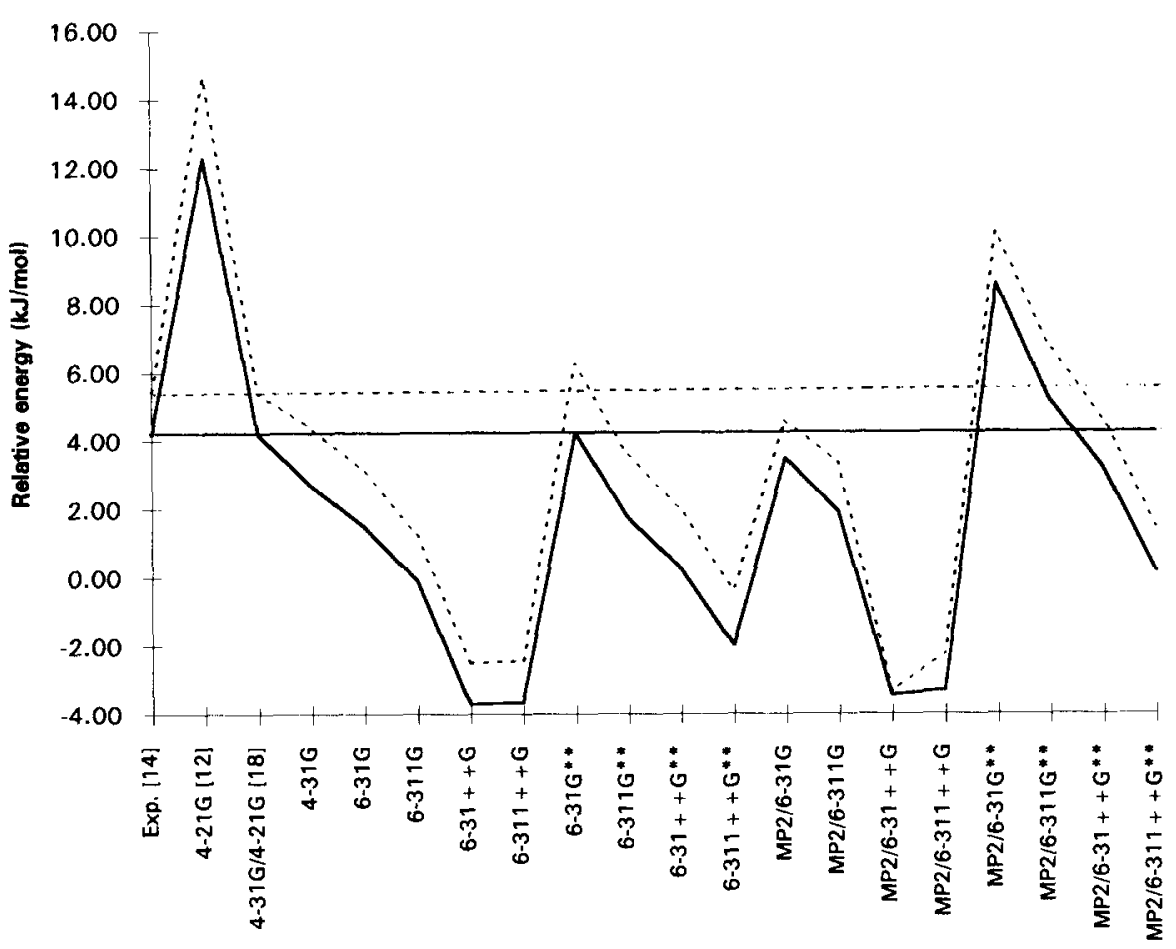

Fig. 2. Experimental and calculated relative energies $\left(\Delta E_{0 \text { (trans-cis })},-; \Delta E_{(\text {(trans-cis })}-\right.$ - $_{\text {) }}$ of methyl nitrite conformers. 
a)

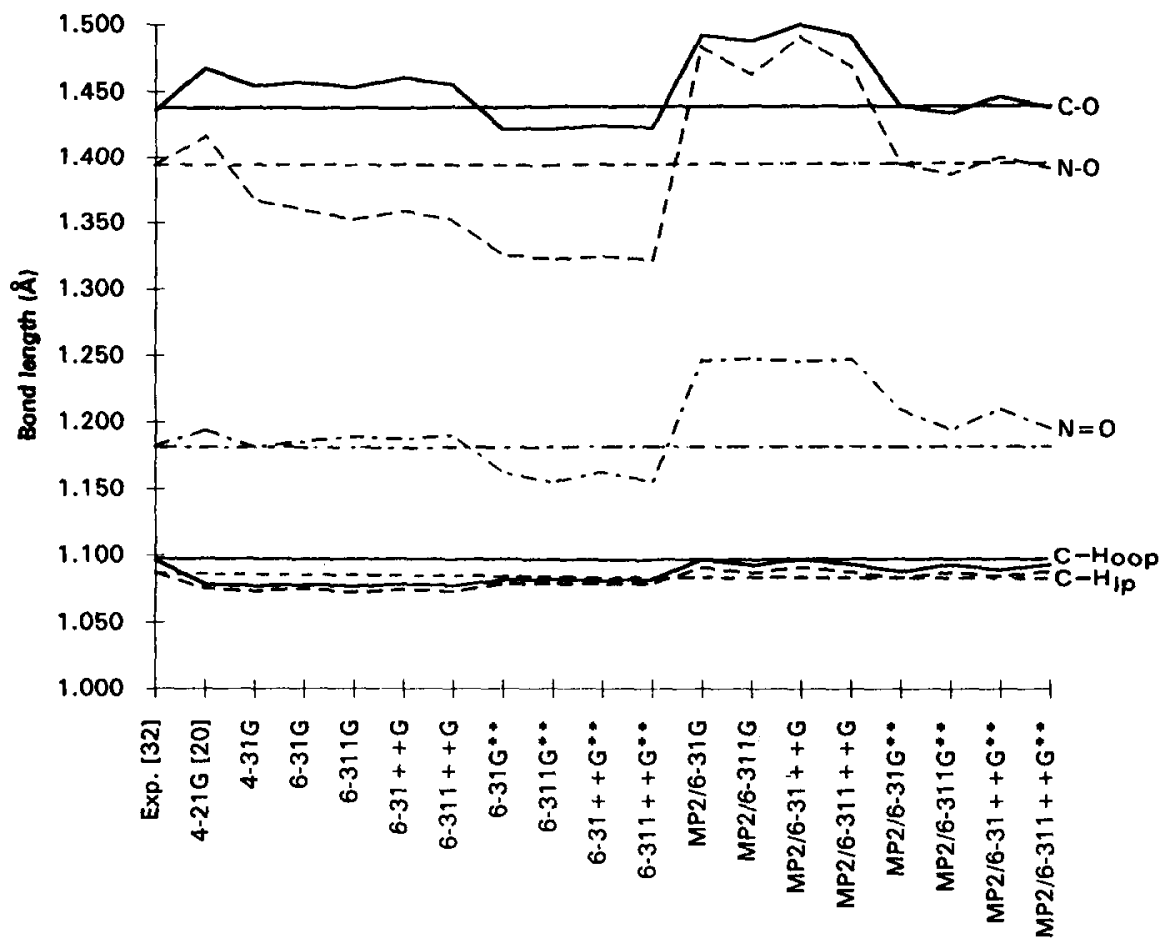

b)

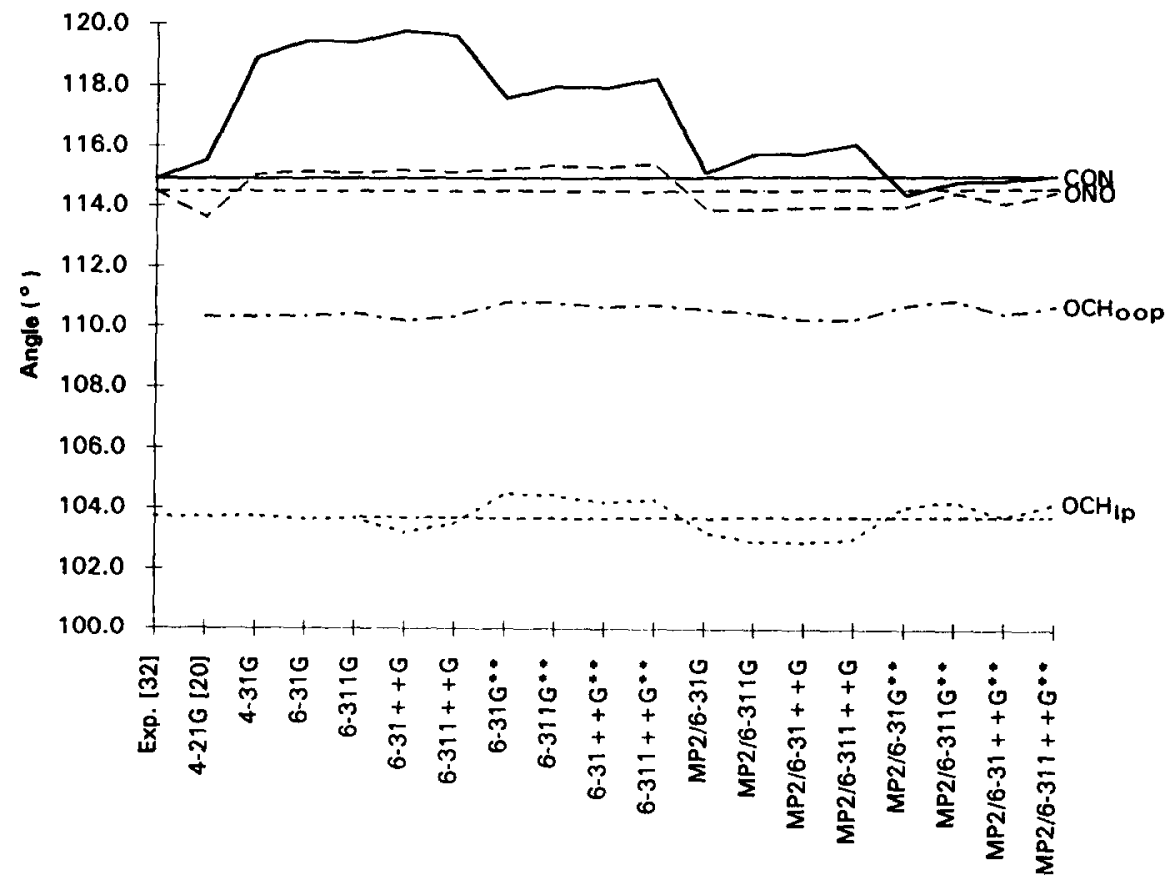

Fig. 3. Basis set dependence of (a) bond lengths and (b) bond angles of methyl nitrite (cis form). 
a)

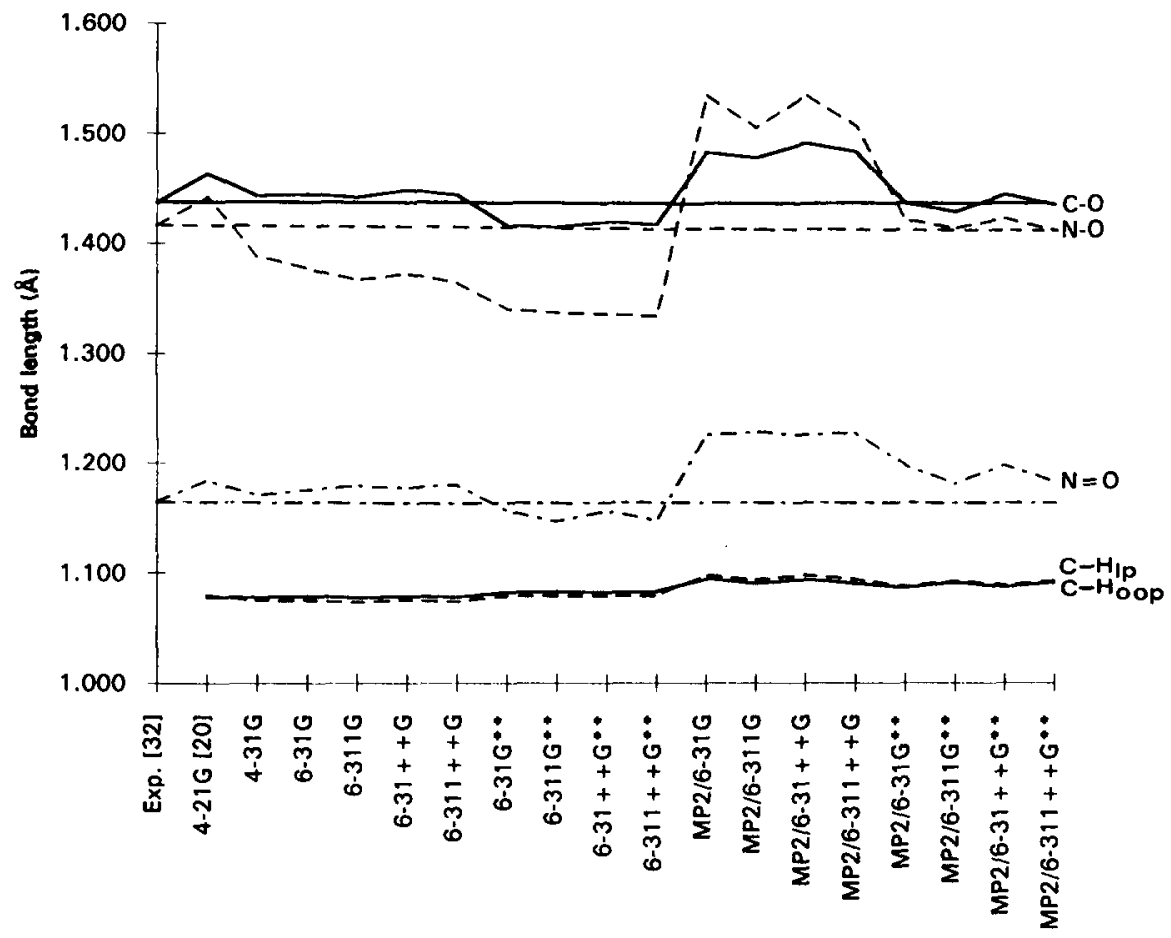

b)

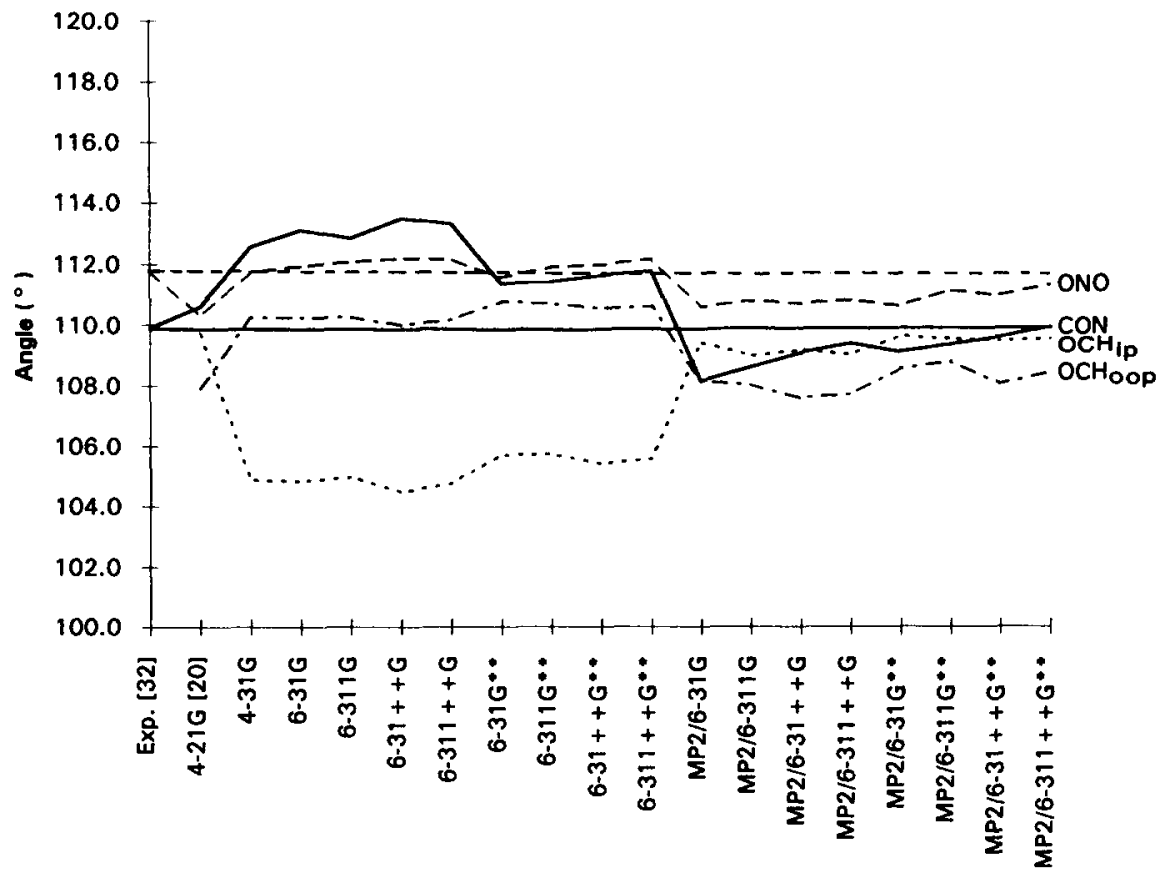

Fig. 4. Basis set dependence of (a) bond lengths and (b) bond angles of methyl nitrite (trans form). 
effects of changing the basis set and considering electron correlation on vibrational properties, and to help in the comparison between the experimental and calculated vibrational spectra.

\section{Computational methods}

The ab initio MO calculations were carried out at both the HF-SCF and MP2 levels of theory with the $6-31 \mathrm{G}$ and $6-311 \mathrm{G}$ basis sets $[23,24]$, without or with the systematic addition of polarization and/or diffuse functions [25] in "heavy atoms" $(\mathrm{C}, \mathrm{N}, \mathrm{O})$ and $\mathrm{H}$, covering all possible combinations, using the GAUSSIAN 92 program system [26] running on a VAX (model 8820 or 6620) computer. The molecular geometries were fully optimized by the force gradient method using Berny's algorithm [27]. The largest residual internal coordinate forces were always less than $3 \times 10^{-4}$ hartree bohr $^{-1}$ (1 hartree $=2625.5001 \mathrm{~kJ} \mathrm{~mol}^{-1} ; 1$ bohr $=5.29177 \times$ $10^{-11} \mathrm{~m}$ ) or hartree $\mathrm{rad}^{-1}$, for bond stretches and angle bends, respectively. The force constants (symmetry internal coordinates) to be used in the normal coordinate analysis were obtained from the $\mathrm{ab}$ initio cartesian harmonic force constants using the program TRANSFORMER [28]. This program was also used to prepare the input data for the normal coordinate analysis programs used in this study (BUILD-G and VIBRAT [29]).

The two-level factororial design analysis was performed using the FACPROB program [30]. The Ein*Sight program was used for explanatory analysis during the principal component analysis (PCA) [31].

\section{Results and discussion}

\subsection{Geometries and energies}

Table 1 shows the calculated and experimentally obtained relative energies of the cis and trans conformers of methyl nitrite. These data are also presented, in a graphical format, in Fig. 2. The previously reported HF-SCF relative energies obtained with the 4-21G basis set and with the 4$31 \mathrm{G}$ basis set at the 4-21G optimized geometries
Table 2

Experimental and MP2 6-311G** calculated geometries of the cis and trans conformers of methyl nitrite

\begin{tabular}{|c|c|c|c|c|}
\hline \multirow[t]{2}{*}{ Parameter } & \multicolumn{2}{|l|}{$\mathrm{CiS}$} & \multicolumn{2}{|l|}{ Trans } \\
\hline & $\operatorname{Exp}[32]$ & Calc. & Exp [32] & Calc. \\
\hline $\mathrm{N}=\mathrm{O}$ & 1.182 & 1.194 & 1.164 & 1.182 \\
\hline $\mathrm{N}-\mathrm{O}$ & 1.394 & 1.389 & 1.415 & 1.415 \\
\hline $\mathrm{C}-\mathrm{O}$ & 1.436 & 1.434 & 1.436 & 1.429 \\
\hline $\mathrm{C}-\mathbf{H}_{\mathrm{i} . \mathrm{p}}$ & 1.087 & 1.087 & & 1.093 \\
\hline $\mathrm{C}-\mathrm{H}_{\text {o.o.p. }}$ & 1.096 & 1.093 & & 1.091 \\
\hline ONO & 114.5 & 114.4 & 111.8 & 111.1 \\
\hline $\mathrm{CON}$ & 114.9 & 114.8 & 109.9 & 109.3 \\
\hline $\mathrm{OCH}_{\text {i.p. }}$ & 103.7 & 104.2 & & 109.5 \\
\hline $\mathrm{OCH}_{\text {o.o.p. }}$ & & 110.9 & & 108.7 \\
\hline
\end{tabular}

a Bond lengths in $\AA$; angles in deg.

$[12,20]$ are also shown in Table 1 and Fig. 2 for comparison. The basis set dependence of the calculated geometries is shown in Figs. 3 and 4, while the experimental geometries of the two forms and those calculated at the MP2 level using the 6$311 \mathrm{G}^{* *}$ basis set are presented in Table 2 . The reason why the MP2/6-311G** results deserve special attention is because among all the possibilities considered, this level of calculation yields the best results, not only for geometries and energies, but also in the case of other properties, like dipole moments and infrared frequencies and intensities, as will be stressed later on.

In order to analyze the contributions of polarization and diffuse functions to the relative conformational energies calculated using the $6-31 \mathrm{G}$ or 6-311G basis set (both at the HF-SCF and MP2 levels), as well as to quantify the effects of the possible interactions between these effects, a TLFD analysis was undertaken based on the data shown in Table 1. In a TLFD analysis, experiments were made at all possible combinations of levels for all factors that are supposed to influence a given response. Table 3 shows the codified designing matrix, corresponding to the data of Table 1. The notation is as follows: Val is related to the valence description, i.e. it indicates whether the $6-31 \mathrm{G}$ or the 6-311G basis was used; Dif and Pol describe whether diffuse or polarization functions were used; Corr indicates whether the calculations were performed at the HF-SCF or MP2 level. 


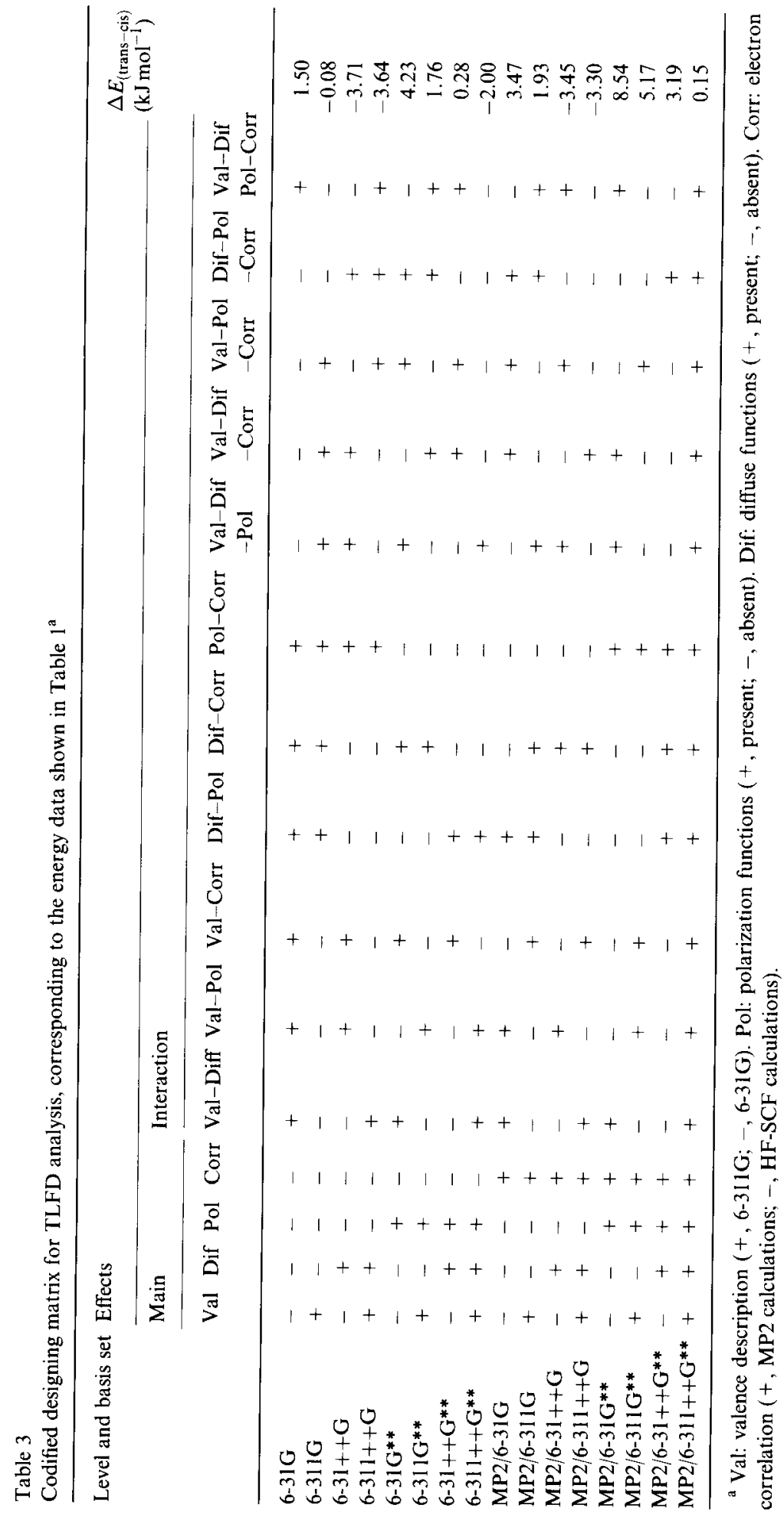


a )

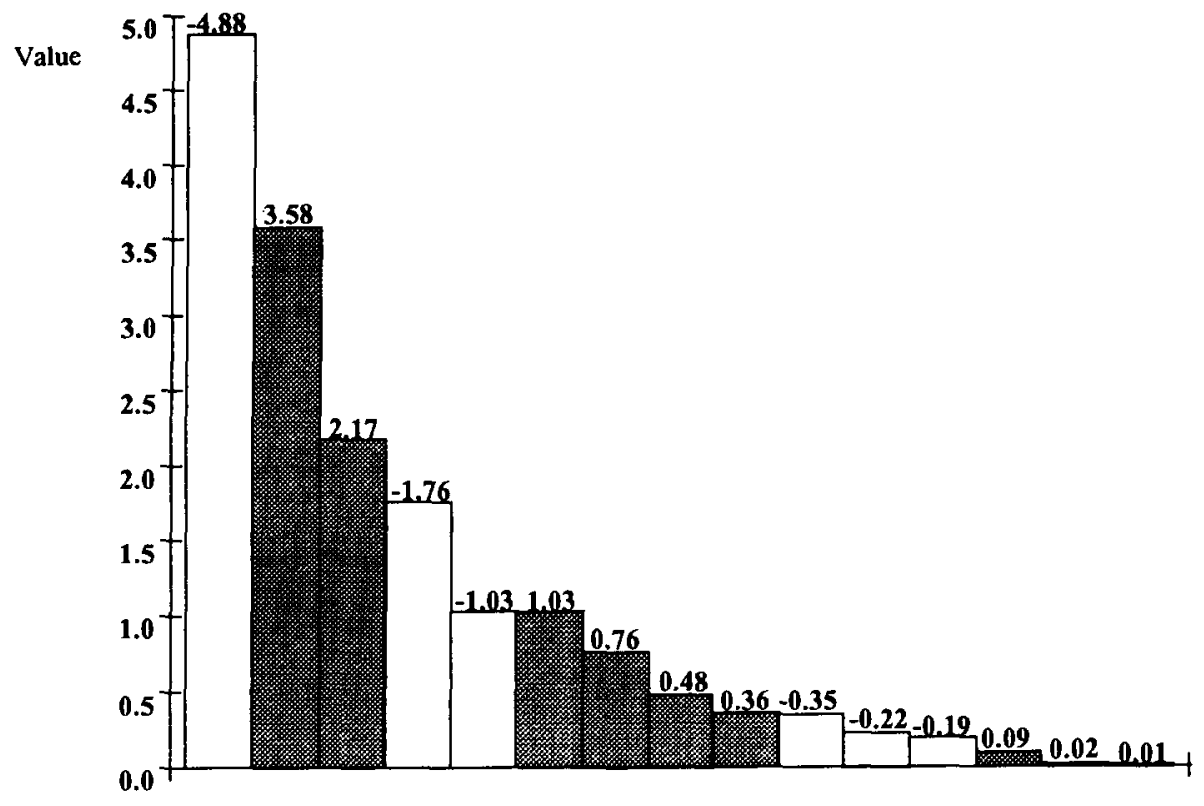

$\begin{array}{lllllllllll}D & P & C & V & \text { VP } & \text { PC } & \text { DC } & \text { VD } & \text { DP } & \text { VDP VPC VC } & \text { DPC VDC VDPC }\end{array}$

Effect

b)
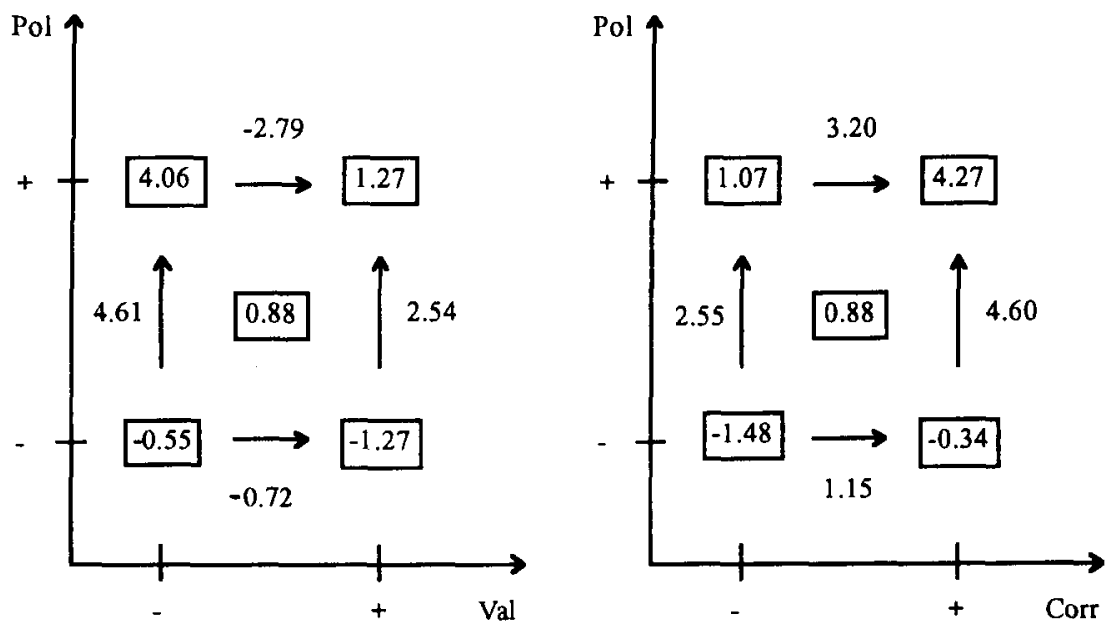

Fig. 5. Results of TLFD chemometrics analysis of the effects of increasing the basis set representation of the valence shell (V, Val), including polarization ( $\mathrm{P}, \mathrm{Pol})$ or diffuse $(\mathrm{D}, \mathrm{Dif})$ functions on the basis and considering electron correlation $(\mathrm{C}$, Corr), on the calculated relative conformational energies $\left(\Delta E_{0(\text { trans-cis) }}\right)$. (a) The values shown $\left(\mathrm{kJ} \mathrm{mol}^{-1}\right)$ are calculated as the differences between the average energies corresponding to the upper and lower levels for each effect or combination of effects considered (for example, the $\mathrm{C}$ principal term is calculated as $\left(\Sigma_{(m p 2)} \Delta E_{0\{\text { (trans-cis })}-\Sigma_{(\mathrm{HF}-\mathrm{SCF})} \Delta E_{\mathrm{o}(\text { trans-cis })} / 8\right)$. (b) Graphs showing the Pol-Val and Pol-Corr conjugated effects, also useful for analyzing the corresponding second-order interaction terms. The values in the boxes correspond to the average values of $\Delta E_{\mathrm{o} \text { (trans-cis) }}\left(\mathrm{kJ} \mathrm{mol}^{-1}\right)$ for the four combinations that simultaneously satisfy the associated level ( + or - ) of the two factors analyzed. The central box contains the mean value of $\Delta E_{0(\text { trans-cis })}$. 
For the calculation of the main and interaction effects of the factors, the corresponding signs are applied to the column of the relative conformational energies, and then the differences between the high level results $(+)$ and the low level results $(-)$ are averaged. The signs of the interaction terms are obtained by the direct product of the main effect signs. The relative importance of each of these effects can be better seen by ordering them on a plot, as in Fig. 5(a). This figure clearly shows that the main effects are by far dominant, although the second-order interaction terms also have some relevance (especially those involving polarization functions) to the relative conformational energies. However, the interaction terms of higher orders appear to be irrelevant. The meaning of the main effects is straightforward. The valence level (i.e. going from a $6-31 \mathrm{G}$ to a $6-311 \mathrm{G}$ basis set) and the inclusion of diffuse functions tend to favour the trans form relatve to the cis conformer. However, both electron correlation and inclusion of polarization functions in the basis sets tend to increase the relative stability of the cis form. The second-order interaction terms do not have such a clear meaning as the main effects, and the best way to analyze their relative importance is to look at the graphs shown in Fig. 5(b). These show that the second-order interaction term Val-Pol represents a decrease of the polarization main effect on going from a $6-31 \mathrm{G}$ to a $6-311 \mathrm{G}$ basis set (3.51 to $2.54 \mathrm{~kJ} \mathrm{~mol}^{-1}$ ). A similar analysis of the secondorder interaction term Pol-Corr indicates that the effect of going from a basis set without polarization functions to a basis set with polarization functions is larger at the MP2 level than at the HF-SCF level of calculation.

Comparing now the calculated and experimental results (see Table 1 and Fig. 2), the first point to note is that the calculated results are clearly better when electron correlation is considered. Indeed, at the MP2 level of theory, only the $6-31++G$ and $6-311++\mathrm{G}$ basis (i.e. those bases having diffuse functions but not polarization functions added) do not predict the cis form as being the more stable conformer. Further, at this level of theory, several bases yield fairly good agreement between the experimental and calculated data $(6-31 \mathrm{G}$, 6$\left.311 \mathrm{G}^{* *}, 6-31++\mathrm{G}^{* *}\right)$. With a single exception,
(6-31++ $\left.+\mathrm{G}^{* *}\right)$ all the results obtained using basis sets containing diffuse functions give very poor results, in general wrongly predicting the trans form as the more stable form. In turn, the best set of results is obtained when polarization functions are presented in the basis set.

Although taking into consideration only the energy data, it cannot be firmly decided which basis set is the most adequate for studying the family of molecules in which we are interested (alkyl nitrites), the results point to the necessity of working at the MP2 level, using a basis set having polarization but not diffuse functions. Indeed, the whole set of results obtained in the present study clearly indicates that such an ideal choice corresponds to the MP2/6-311 G** level of theory.

The fact that the best agreement between the calculated and experimental data shown in Table 1 refers to the 4-31G energies calculated at the 4$21 \mathrm{G}$ optimized geometries [20] must be considered fortuitous, since there is an obvious internal inconsistency in this kind of calculation. However, the properly calculated 4-21G and 4-31G conformer energy differences are respectively much higher and somewhat lower than the experimental value (12.27 [12] and $2.69 \mathrm{~kJ} \mathrm{~mol}^{-1}$, vs. $4.18 \mathrm{~kJ} \mathrm{~mol}^{-1}$ [14]).

The experimental methyl top barriers to internal rotation in the cis and trans form are $8.74 \mathrm{~kJ} \mathrm{~mol}^{-1}$ and $120-790 \mathrm{~J} \mathrm{~mol}^{-1}$, respectively $[6,20]$. As already mentioned, the large difference between these two values has been interpreted as a result of the existence of an $\mathrm{C}-\mathrm{H} \cdots \mathrm{N}_{\mathrm{lp}}$ stabilizing interaction at the rotational transition state to methyl internal rotation in the trans conformer. This explanation relies on the results of the previously reported HF-SCF 4-21G calculations [20], which have predicted the methyl group in the trans conformer to assume the staggered form with respect to the $\mathrm{O}-\mathrm{N}$ bond, since the precise orientation of the methyl group in this conformer has not yet been determined experimentally. However, although the more extended HF-SCF calculations using the 6$31 \mathrm{G}$ and $6-311 \mathrm{G}$ basis sets (now undertaken) also predict the staggered geometry of the methyl group (form IV in Fig. 1) as corresponding to the lower energy conformation in the trans conformer, the consideration of electron correlation at the MP2 
a)

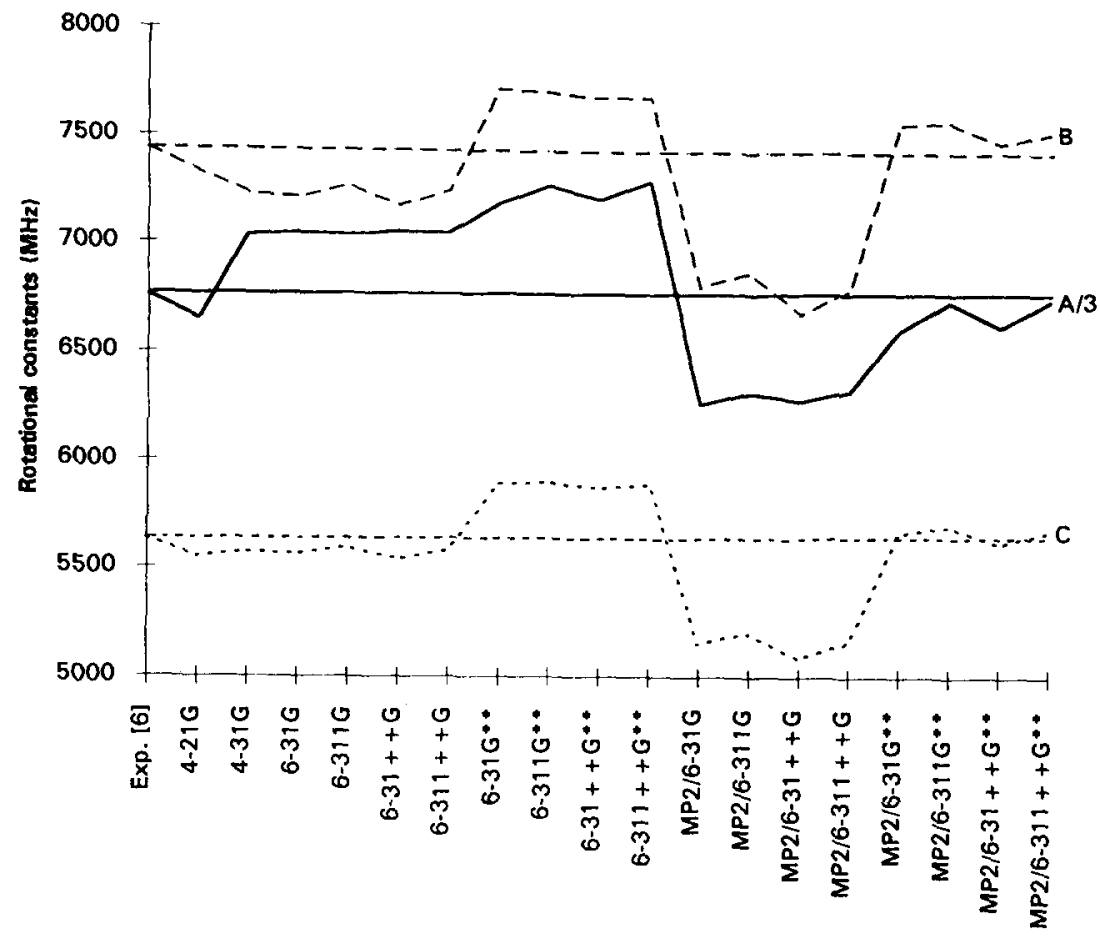

b)

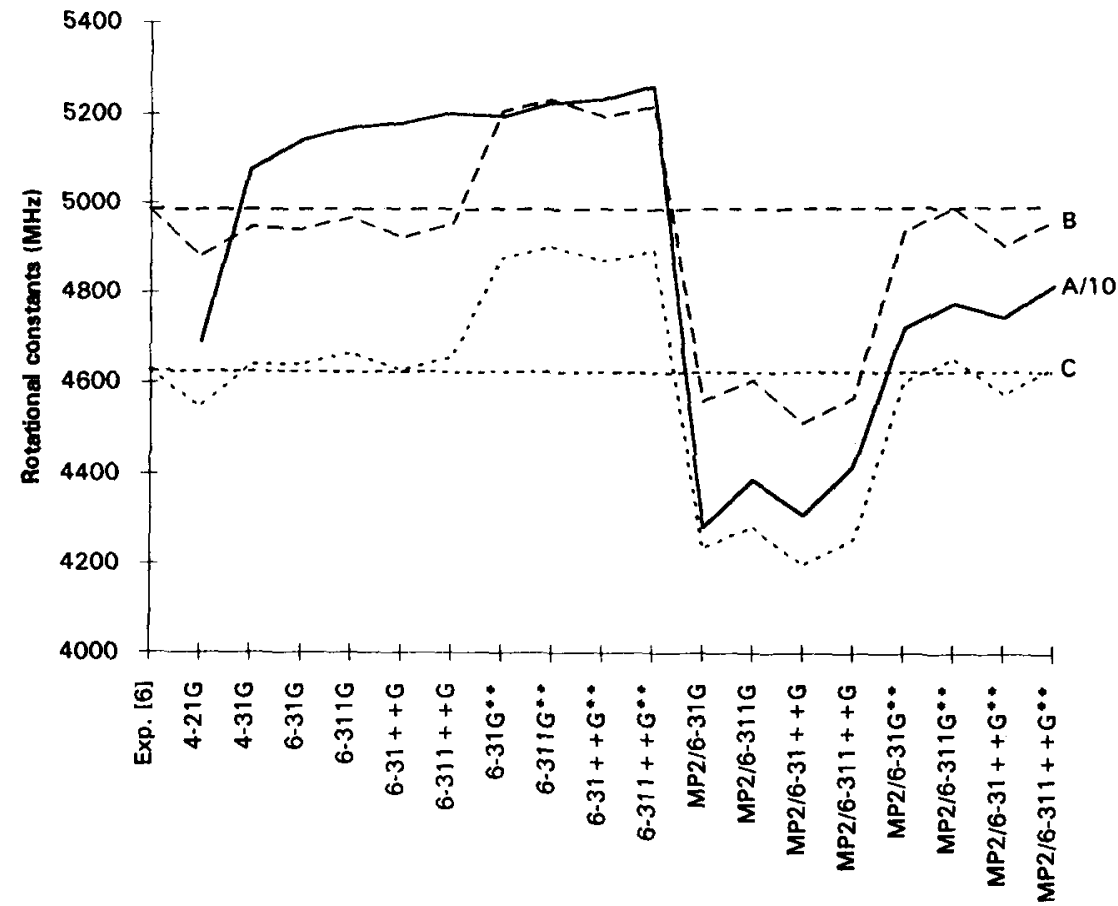

Fig. 6. Experimental and calculated rotational constants (MHz) for (a) cis- and (b) trans-methyl nitrite. The experimental and MP2 6$311 \mathrm{G}^{* *}$ calculated rotational constants are respectively: cis, 20272.46 (A), 7437.81 (B), 5630.58 (C) MHz [6] vs. 20173.22 (A), 7556.22 (B), 5694.75 (C) MHz; trans, 4987.49 (B), 4627.43 (C) MHz [6] vs. 4778.59 (A), 4994.46 (B), 4656.16 (C) MHz. 
level of theory leads to a more stable eclipsed methyl group (form II in Fig. 1). Thus, the highest level calculations indicate that the $\mathrm{C}-\mathrm{H} \cdots \mathrm{N}_{\mathrm{lp}}$ stabilizing interaction is sufficiently strong to invert the relative order of stability of the staggered vs. eclipsed methyl conformations in the trans conformer. The MP2 6-311G** calculated methyl top barriers are $9.54 \mathrm{~kJ} \mathrm{~mol}^{-1}$ for the cis form and $1.57 \mathrm{~kJ} \mathrm{~mol}^{-1}$ for the trans conformer. Thus, the MP2 6-311G** calculations are able to predict the methyl energy barriers in both conformers in very reasonable agreement with experiment. The values previously obtained at the HF-SCF 4-21G level [20] were $8.65 \mathrm{~kJ} \mathrm{~mol}^{-1}$ (cis) and $749 \mathrm{~J} \mathrm{~mol}^{-1}$ (trans), but this latter value assumes the equilibrium and the methyl rotation transition state structures to be in the wrong order.

Considering the good agreement between the experimental and the MP2 6-311G** calculated methyl energy barriers for the two conformers of methyl nitrite, it could be expected that the calculated conformational entropy difference $\left(\Delta S_{\text {(trans-cis) }}\right)$ was also in good agreement with the experimental data. Indeed, the MP2 6-311G** calculated entropy contents of the cis and trans conformers of methyl nitrite are respectively 277.872 and $287.376 \mathrm{~J} \mathrm{~K}^{-1} \mathrm{~mol}^{-1}$, leading to a $\Delta S_{\text {(trans-cis) }}=$ $9.50 \mathrm{~J} \mathrm{~K}^{-1} \mathrm{~mol}^{-1}$, which is in quantitative agreement with the experimental value $\left(9.62 \mathrm{~J} \mathrm{~K}^{-1} \mathrm{~mol}^{-1}[6]\right)$.

The results of the analyses of the basis set dependence and importance of electron correlation on the molecular geometries of the two conformers of methyl nitrite are particularly interesting (Figs. 3 and 4). As could be anticipated, the most sensitive parameters are those involving atoms other than hydrogen atoms. The $\mathrm{N}-\mathrm{O}$ bond length is systematically underestimated at the SCF level, while it is overestimated at the MP2 level except when polarization functions are included in the basis set. In turn, the changes in both the $\mathrm{N}=\mathrm{O}$ and $\mathrm{C}-\mathrm{O}$ bond lengths follow a different pattern: at the SCF level they are calculated close to their experimental values (a slight overestimation can be noted in the absence of polarization functions, and a slight underestimation is observed in the presence of these functions); when electron correlation is considered, however, these bond lengths are considerably overestimated unless polarization functions are present; in this latter case, the agreement between the experimental and calculated values is very good. The valence angles, in particular the ONO and CON angles, are calculated to be larger at the SCF than at the MP2 level (the exception is the $\mathrm{OCH}$ in-plane angle in the trans conformer, which follows the opposite trend - Fig. 4(b)). The better agreement between the experimental and the MP2 calculated angles is clearly seen in the case of the CON angle; in this instance, the consideration of the electron correlation makes negligible the large error $\left(\approx 3-4^{\circ}\right)$ systematically found in the SCF calculated values.

On the whole, the best structures are computed at the MP2 6-311G** and MP2 6-311++G** levels, which yield practically the same results. Indeed, in these cases, almost perfect agreement between the calculated and observed structural parameters are reached (the $\mathrm{N}=\mathrm{O}$ bond length is calculated to be slightly longer). For instance, a measure of the quality of the results obtained by using the following expression, based on the relative errors

$\mathrm{D}=\left\{\sum\left[\left(\text { calc }_{\mathrm{i}}-\exp _{\mathrm{i}}\right) / \exp _{\mathrm{i}}\right]^{2}\right\}^{1 / 2}$

yields $D$ values for the above-mentioned basis sets of about 0.011 and 0.17 , respectively for the cis and trans conformers, which are at least two times smaller than the $D$ values obtained with any other basis set and/or level of theory used. The excellent quality of the MP2 6-311G** and MP2 6-311 $+\mathrm{G}^{* *}$ structural results may also be observed by looking at the experimental vs. calculated rotational constants (Fig. 6).

Comparing now the structural parameters calculated for the two conformers (Table 2), it can be seen that, while $\mathrm{N}=\mathrm{O}, \mathrm{C}-\mathrm{O}$ and $\mathrm{C}-\mathrm{H}$ out-of-plane bond lengths increase on going from the trans to the cis form, both the $\mathrm{N}-\mathrm{O}$ and $\mathrm{C}-\mathrm{H}$ in-plane bond lengths become shorter. All these changes are consistent with the presence, in the cis conformer, of a hyperconjugation involving the methyl out-of-plane hydrogen atoms and the $\mathrm{C}-\mathrm{O}-\mathrm{N}=\mathrm{O}$ fragment.

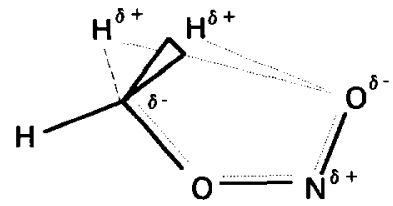


The observed reduction in the $\mathrm{C}-\mathrm{H}$ in-plane bond length results mainly from an increased scharacter of the carbon orbital used to make the bond with the in-plane hydrogen atom, and is an indirect consequence of the above-mentioned hyperconjugative effect present in the cis form, although the $\mathrm{C}-\mathrm{H}_{\mathrm{i} . \mathrm{p}} \cdots \mathrm{N}_{\mathrm{lp}}$ interaction present in the trans form also contributes in some extent to the lengthening of this bond length in the latter conformer. The changes in valence angles associated with the trans $\rightarrow$ cis conversion depend mainly on steric requirements. Indeed, all the $\mathrm{O}-$ $\mathrm{N}=\mathrm{O}, \mathrm{C}-\mathrm{O}-\mathrm{N}$ and $\mathrm{O}-\mathrm{C}-\mathrm{H}$ out-of-plane angles are larger in the cis conformer than in the trans form, as the methyl out-of-plane hydrogen atoms and the $\mathrm{N}=\mathrm{O}$ moiety are much closer in this conformer. However, the decrease observed in the $\mathrm{O}-\mathrm{C}-\mathrm{H}$ in-plane angle upon trans $\rightarrow$ cis conversion occurs not only to compensate the changes in the remaining angles, but mainly because the $\mathrm{C}$ $\mathrm{H}_{\text {i.p. }} \cdots \mathrm{N}_{\mathrm{lp}}$ interaction which is present in the trans form has no counterpart in the cis form.

As will be stressed later on, the conclusions now extracted from the structural results are further supported by the analysis of the calculated electron distribution in the two forms, and also by looking at the relative values of the $\nu \mathrm{N}=\mathrm{O}, \nu \mathrm{N}-\mathrm{O}$ and $\nu \mathrm{C}$ $\mathrm{O}$ stretching vibrational frequencies, which correlate well with the correspondent bond lengths (a lower vibrational frequency correlates with a longer bond).

\subsection{Charge distribution analysis}

The general quality of a given basis set and the importance of electron correlation must be reflected very clearly in the calculated electron distribution. Dipole moments and infrared intensities

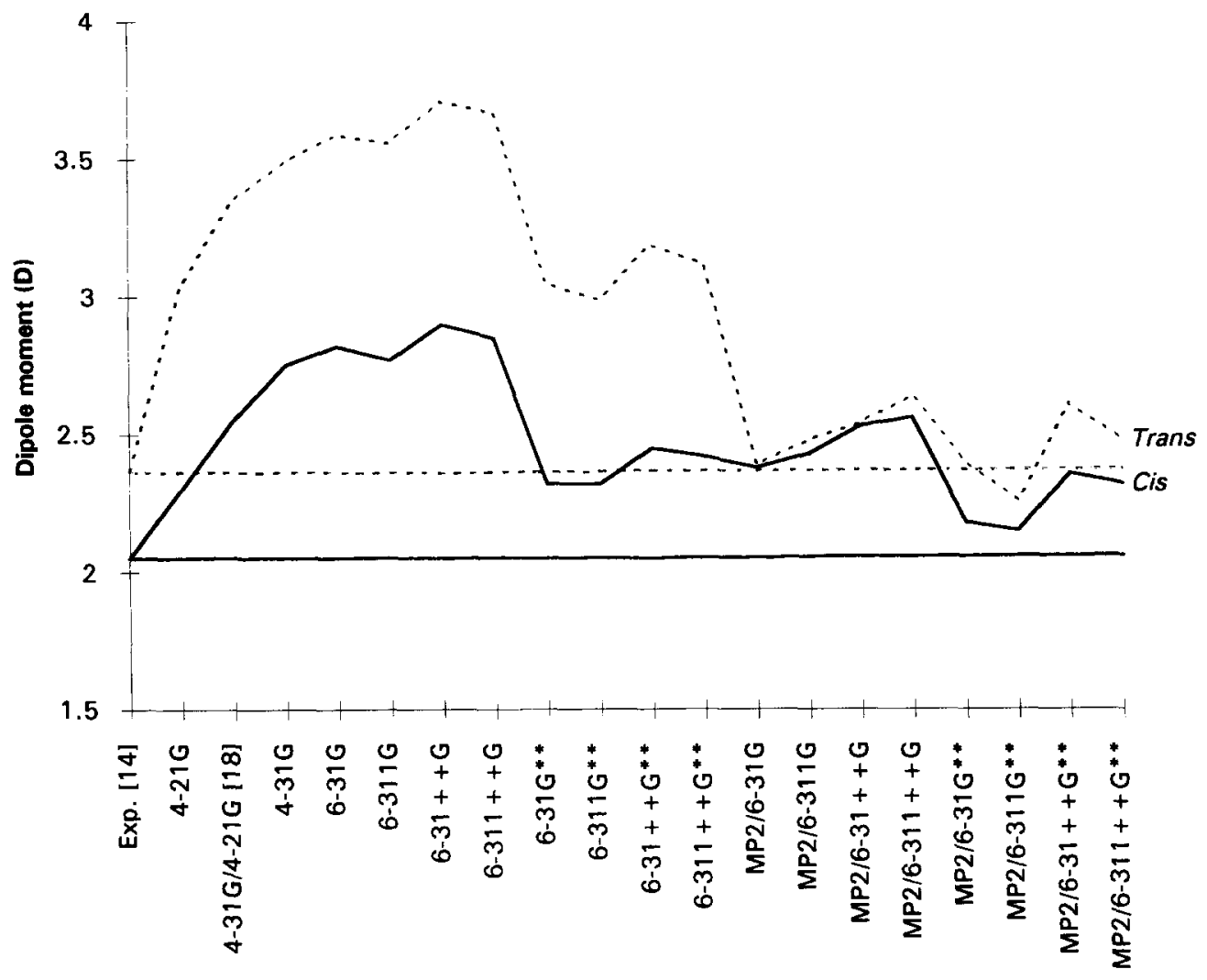

Fig. 7. Basis set dependence of the dipole moment (Debye; $1 \mathrm{D}=1 / 3 \times 10^{-2} \mathrm{C} \mathrm{m}$ ) of cis (-) and trans (- -) methyl nitrite. 
a)

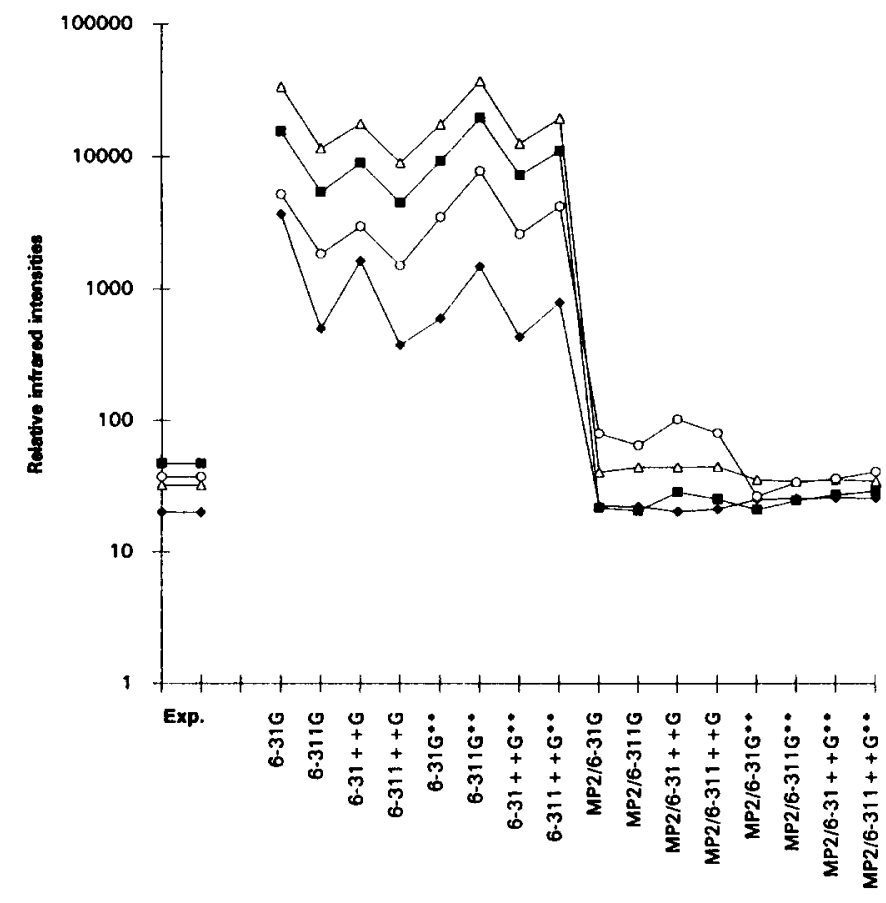

b)

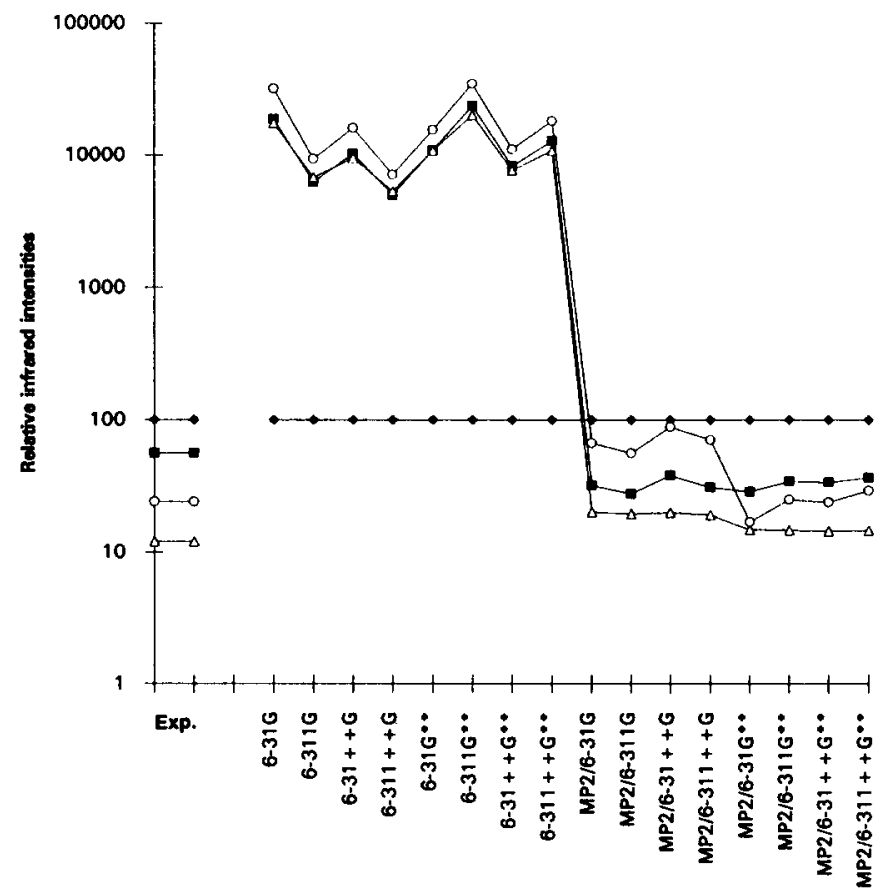

Fig. 8. Experimental and calculated infrared relative intensities (arbitrary units) of some selected infrared bands ( $\mathbb{Q}, \nu \mathrm{N}=\mathrm{O} ; \mathrm{O}, \nu \mathrm{N}-\mathrm{O}$; $\triangle, \nu \mathrm{C}-\mathrm{O} ; \diamond, \delta \mathrm{O}=\mathrm{N}-\mathrm{O}$ ). (a) cis form; (b) trans form. In the normalization criterion used the intensity of the trans $\delta \mathrm{O}=\mathrm{N}-\mathrm{O}$ bending mode is considered to be equal to 100 . 
(a)
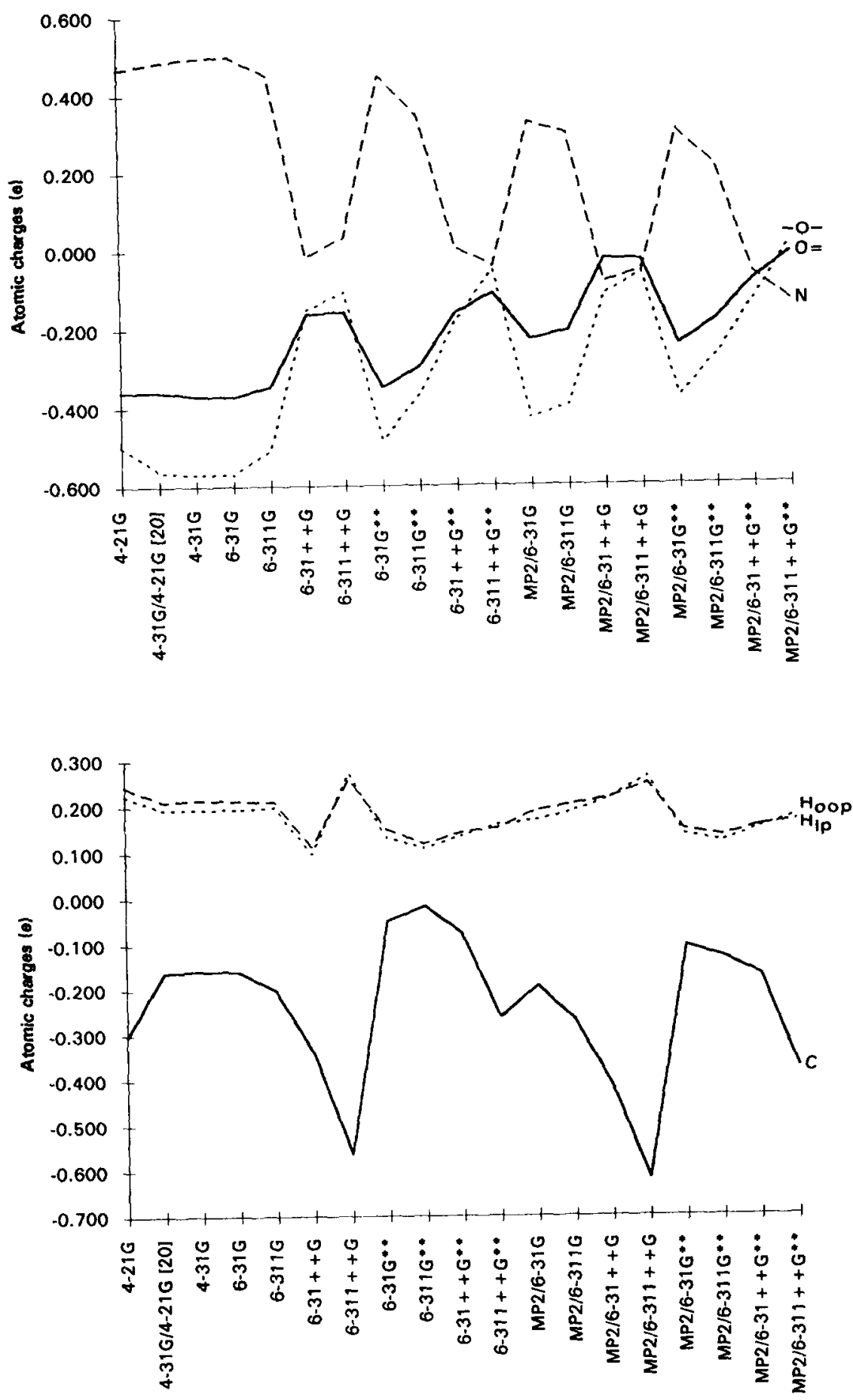

Fig. 9. Basis set dependence of the atomic charges $\left(e=1.6021892 \times 10^{-19} \mathrm{C}\right)$ of (a) cis- and (b) trans-methyl nitrite 
J.B.P. da Silva et al./Journal of Molecular Structure 375 (1996) 153-180

(b)
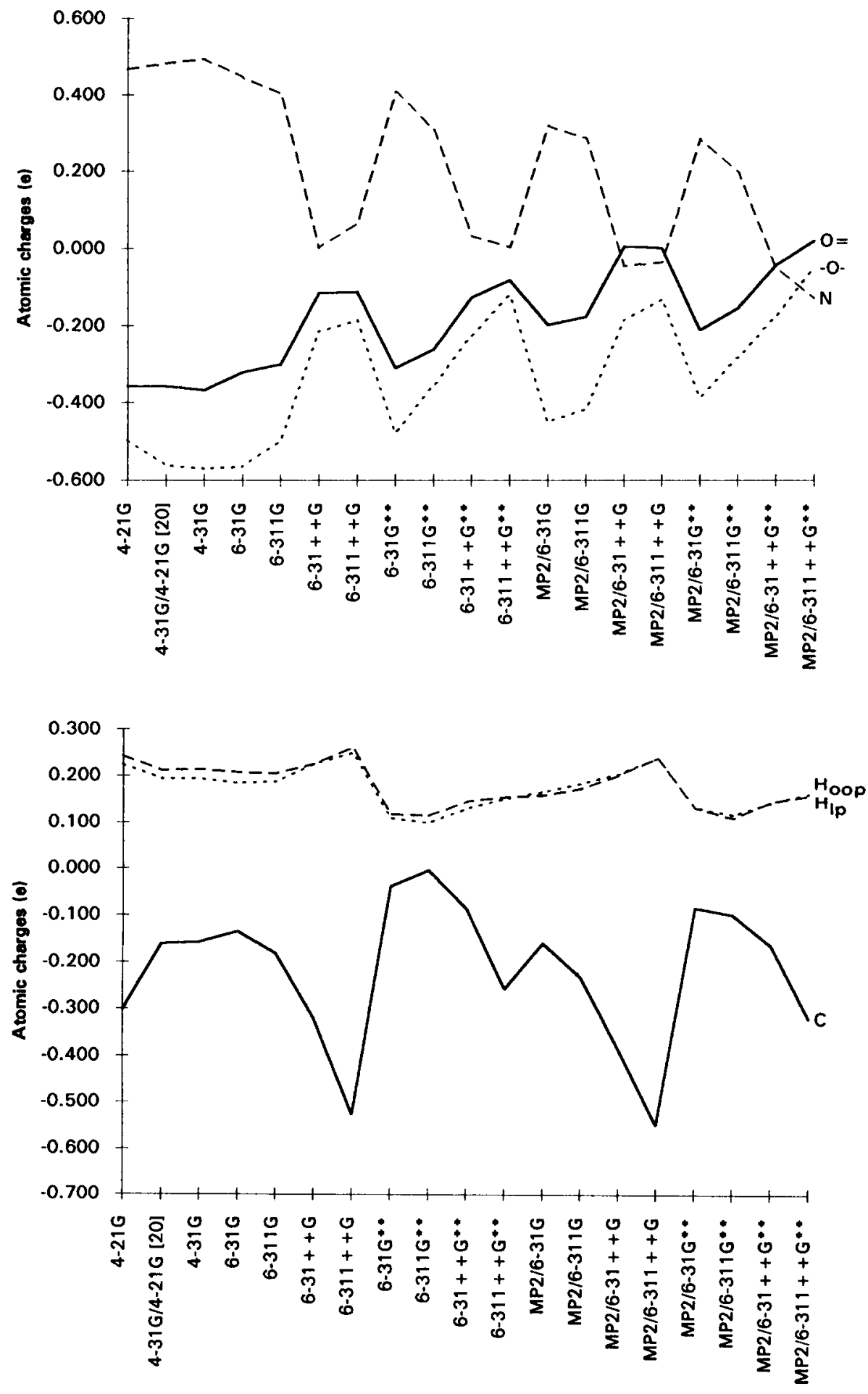

Fig. 9. Continued. 
Table 4

Experimental and MP2 6-311G** calculated dipole moments and MP2 $6-311 \mathrm{G}^{* *}$ calculated atomic charges of the cis and trans conformers of methyl nitrite ${ }^{a}$

\begin{tabular}{llrlr}
\hline Parameter & \multicolumn{2}{l}{ Cis } & & \multicolumn{2}{l}{ Trans } \\
& Exp. [14] & Calc. & Exp. [14] & Calc. \\
\hline Charges & & & & \\
$\mathrm{O}=$ & -0.184 & & -0.155 \\
$\mathrm{~N}$ & & 0.210 & & 0.197 \\
$-\mathrm{O}-$ & & -0.273 & & -0.283 \\
$\mathrm{C}$ & & -0.130 & & 0.099 \\
$\mathrm{H}_{\text {i.p. }}$ & & 0.134 & & 0.109 \\
$\mathrm{H}_{\text {o.o.p. }}$ & & 0.121 & & 0.116 \\
Dipole moment & 2.05 & 2.15 & 2.37 & 2.26 \\
\hline
\end{tabular}

${ }^{a}$ Charges in units of $e\left(e=1.6021892 \times 10^{-19} \mathrm{C}\right)$; dipole moments in Debyes $\left(1\right.$ Debye $=1 / 3 \times 10^{-2} \mathrm{Cm}$ ).

are two distinct observables which may be used to evaluate the global quality of the electron distribution obtained in a calculation. In addition, although they cannot be directly compared with experimental data, calculated atomic charges have the advantage of providing a very intuitive way of looking at the electron charge distribution within the molecule. Moreover, the changes in the calculated charges with the conformation can be, in general, correlated in a very simple way with the relative importance of the various possible canonical structures contributing to each conformer. Figs. 7-9 show the variation of the calculated dipole moments, intensities of selected infrared bands and Mulliken atomic charges with the basis set and level of theory used to perform the calculations. Table 4 presents the results (atomic charges and dipole moments) obtained at the MP2 6$311 \mathrm{G}^{* *}$ level.

At the HF-SCF level, the calculated dipole moments of both conformers are systematically overestimated (Fig. 7). The agreement between the experimental values and the calculated results improves considerably when electron correlation is considered (MP2 data), the best results being those obtained with the 6-311 $\mathrm{G}^{* *}$ basis set, which differ from the experimental values by less than $5 \%$. It is interesting to note that, besides the overestimation in the dipole moments calculated at HF-SCF level, the difference between the dipole moments
$\left(\Delta \mu_{\text {trans-cis }}\right)$ is also considerably overstimated. This results mainly from the fact that, as referred to above, the HF-SCF calculations wrongly predict the geometry of the methyl group in the trans form, since the staggered geometry has a significantly higher dipole moment (e.g. MP2 6-311G** dipole moments for the staggered and ecliped methyl group geometries in the trans conformer are respectively 2.87 and 2.26 Debyes).

The calculated infrared relative intensities show very different patterns in accordance with the inclusion or not of electron correlation. The results shown in Fig. 8, where the relative intensities of the $\nu \mathrm{N}=\mathrm{O}, \nu \mathrm{C}-\mathrm{O}, \nu \mathrm{N}-\mathrm{O}$ and $\delta \mathrm{O}=\mathrm{N}-\mathrm{O}$ vibrations are plotted and compared with the corresponding experimental values, clearly indicate that inclusion of electron correlation is essential to obtain a good prediction of the experimental infrared intensities of methyl nitrite. Although the relative intensity of $\nu \mathrm{N}=\mathrm{O}$ in both conformers is significantly underestimated, the calculated MP2 results obtained with the basis sets which include polarization functions, in particular those obtained with the 6$311 \mathrm{G}^{* *}$ basis set, are in excellent general agreement with the experimental data.

The analysis of the basis set dependence of atomic charges clearly reveals that when diffuse functions are used the general quality of the results strongly deteriorates. Indeed, in this case, the charges on the oxygen atoms are systematically calculated to be less negative than that of the carbon atom, which is certainly a very unrealistic result. Note that in the case of both the MP2 6$31++\mathrm{G}$ and MP2 6-311++G calculations even the charge of the nitrogen atom becomes more negative than that of the $\mathrm{O}=$ atom (in both conformers), and very close to that of the $\mathrm{O}-$ atom (in the cis form) (Fig. 9). In the case of those calculations undertaken without diffuse functions, the more extended the basis set and the better the level of theory used, the smaller the positive charge of the nitrogen atom and the negative charges on the oxygen atoms; the charges on the carbon atom show a more complex pattern of variation, becoming more negative upon inclusion of electron correlation and less negative by adding polarization functions (on the whole, these effects lead to less negative carbon atom charges when going from the 
HF-SCF 6-31G or HF-SCF 6-311G wavefunctions to the MP2 $6-31 G^{* *}$ or MP2 $6-311 G^{* *}$ wavefunctions, respectively). It should be noted that the general reduction with the basis set size and level of calculation observed in the absolute magnitudes of the atomic charges obtained with those basis sets which do not yield obvious unrealistic electron distributions (i.e. all but those bases which include diffuse functions) are consistent with the relative values of the calculated dipole moments discussed above.

The comparison of the atomic charges for the cis (I) and trans (II) conformers (Table 4) reinforces our interpretation of the structural data. In particular, it is consistent with the presence, in the cis form, of the above-discussed hyperconjugation involving the out-of-plane hydrogen atoms and the $\mathrm{C}-\mathrm{O}=\mathrm{N}-\mathrm{O}$ fragment. Thus, on gooing from the trans to the cis conformer, the charges of the $\mathrm{O}=$ and $\mathrm{C}$ atoms become more negative, while those of the out-of-plane hydrogen atoms and of the $\mathrm{N}$ atom become more positive. Interestingly, the calculations also indicate that the $-\mathrm{O}$ - atom becomes slightly more negative upon trans $\rightarrow$ cis isomerization, while the in-plane hydrogen atom becomes more positive. The absence in the cis form of the $\mathrm{C}-\mathrm{H}_{\text {i.p. }} \cdots \mathrm{N}_{\mathrm{lp}}$ interaction may justify, at least in part, the increase in the positive charge of the in-plane hydrogen atom in this form. In addition, it is also possible that, in the cis conformer, an interaction between the in-plane hydrogen and the $\mathrm{C}-\mathrm{O}$ bond (or specifically with the $-\mathrm{O}-$ atom) leading to a release of electron charge from the hydrogen atom is also operating. Such an interaction may also partially contribute to the considerably small $\mathrm{OCH}$ in-plane angle in this conformer $\left(\approx 104^{\circ}\right.$ - Table 2$)$, and may be similar in nature to that found in methanol [33], and methoxy ethers and esters [34,35].

The results of the overlap electron populations reinforce our previous conclusions on the specificity of the effects operating in each conformer: hyperconjugation in the cis form, and $\mathrm{C}-\mathrm{H}_{\text {i.p. }} \cdots$ $\mathrm{N}_{\mathrm{lp}}$ interaction in the trans form. Indeed, the sum of the overlap populations between the $\mathrm{H}_{\text {o.o.p. }}$ and carbon atoms and the $\mathrm{O}=$ atom, which may be considered a good probe of the hyperconjugative effect, is $0.0277 e$ in the cis form and only $0.0060 e$ in the trans conformer. In turn, the overlap population between the $\mathrm{H}_{\text {i.p. }}$ and the $\mathrm{N}$ atoms is much larger in the trans than in the cis form $(0.0160 e$ vs. $0.0039 e$ ).

Table 5

Definition of the internal symmetry coordinates used in the normal coordinate analysis ${ }^{\mathrm{a}}$

\begin{tabular}{|c|c|c|c|}
\hline Coordinate & & Symmetry & Definition \\
\hline $\mathbf{S}_{1}$ & $\nu \mathrm{N}=\mathrm{O}$ & $A^{\prime}$ & $\nu \mathrm{N}=\mathrm{O}$ \\
\hline $\mathrm{S}_{2}$ & $2 \mathrm{~N}-\mathrm{O}$ & $A^{\prime}$ & $\nu \mathrm{N}-\mathrm{O}$ \\
\hline $\mathrm{S}_{3}$ & $\nu \mathrm{C}-\mathrm{O}$ & $A^{\prime}$ & $\nu \mathrm{C}-\mathrm{O}$ \\
\hline $\mathrm{S}_{4}$ & $\nu \mathrm{CH}_{3}$ as. & $A^{\prime}$ & $2 \nu \mathrm{C}-\mathrm{H}_{\text {i.p. }}-\nu \mathrm{C}-\mathrm{H}_{\text {o.o.p. }}-\nu \mathrm{C}-\mathrm{H}_{\text {o.o.p. }}^{\prime}$ \\
\hline $\overrightarrow{S_{5}}$ & $\nu \mathrm{CH}_{3}$ as. & $A^{\prime \prime}$ & $\nu \mathrm{C}-\mathrm{H}_{\text {o.o.p }}-\nu \mathrm{C}-\mathrm{H}_{\text {o.o.p. }}^{\prime}$ \\
\hline$S_{6}$ & $\nu \mathrm{CH}_{3} \mathrm{~s}$ & $A^{\prime}$ & $\nu \mathrm{C}-\mathrm{H}_{\text {i.p. }}+\nu \mathrm{C}-\mathrm{H}_{\text {o.o.p. }}+\nu \mathrm{C}-\mathrm{H}_{\text {o.o.p. }}^{\prime}$ \\
\hline $\mathrm{S}_{7}$ & $\delta \mathrm{O}=\mathrm{N}-\mathrm{O}$ & $A^{\prime}$ & $\delta \mathrm{O}=\mathrm{N}-\mathrm{O}$ \\
\hline $\mathrm{S}_{8}$ & $\delta \mathrm{N}-\mathrm{O}-\mathrm{C}$ & $A^{\prime}$ & $\delta \mathrm{N}-\mathrm{O}-\mathrm{C}$ \\
\hline$S_{9}^{0}$ & $\delta \mathrm{CH}_{3}$ as. & $A^{\prime}$ & $2 \delta \mathrm{H}_{\text {o.o.p. }}-\mathrm{C}-\mathrm{H}_{\text {o.o.p. }}^{\prime}-\delta \mathrm{H}_{\text {i.p. }}-\mathrm{C}-\mathrm{H}_{\text {o.o.p. }}-\delta \mathrm{H}_{\text {i.p. }}-\mathrm{C}-\mathrm{H}_{\text {o.o.p. }}^{\prime}$ \\
\hline $\mathrm{S}_{10}$ & $\delta \mathrm{CH}_{3}$ as. & $A^{\prime \prime}$ & $\delta \mathbf{H}_{\text {i.p. }}-\mathbf{C}-\mathbf{H}_{\text {o.o.p. }}-\delta \mathbf{H}_{\text {i.p. }}-\mathbf{C}-\mathbf{H}_{\text {o.o.p. }}^{\prime}$ \\
\hline $\mathbf{S}_{11}$ & $\delta \mathrm{CH}_{3} \mathrm{~s}$ & $A^{\prime}$ & $\begin{array}{l}\delta \mathrm{H}_{\text {o.o.p }}-\mathrm{C}-\mathrm{H}_{\text {o.o.p. }}^{\prime}+\delta \mathrm{H}_{\text {i.p. }}-\mathrm{C}-\mathrm{H}_{\text {o.o.p. }}+\delta \mathrm{H}_{\text {i.p. }}-\mathrm{C}-\mathrm{H}_{\text {o.o.p. }}^{\prime}-\delta \mathrm{C}-\mathrm{C}-\mathrm{H}_{\text {i.p. }}- \\
\delta \mathrm{C}-\mathrm{C}-\mathrm{H}_{\text {o.o.p. }}-\delta \mathrm{C}-\mathrm{C}-\mathrm{H}_{\text {o.o.p. }}^{\prime}\end{array}$ \\
\hline$S_{12}$ & $\gamma \mathrm{CH}_{3}$ & $A^{\prime}$ & $2 \delta \mathrm{C}-\mathrm{C}-\mathrm{H}_{\text {i.p. }}-\delta \mathrm{C}-\mathrm{C}-\mathrm{H}_{\text {o.o.p. }}-\delta \mathrm{C}-\mathrm{C}-\mathrm{H}_{\text {o.o.p. }}^{\prime}$ \\
\hline $\mathrm{S}_{13}$ & $\gamma \mathrm{CH}_{3}$ & $A^{\prime \prime}$ & $\delta \mathrm{C}-\mathrm{C}-\mathrm{H}_{\text {o.o.p. }}-\delta \mathrm{C}-\mathrm{C}-\mathrm{H}_{\text {o.o.p. }}^{\prime}$ \\
\hline$S_{14}$ & $\tau \mathrm{N}-\mathrm{O}$ & $A^{\prime \prime}$ & $\tau \mathrm{O}=\mathrm{N}-\mathrm{O}-\mathrm{C}$ \\
\hline $\mathbf{S}_{15}$ & $r \mathrm{C}-\mathrm{O}$ & $A^{\prime \prime}$ & $\tau \mathrm{N}-\mathrm{O}-\mathrm{C}-\mathrm{H}_{\text {i.p. }}+\tau \mathrm{N}-\mathrm{O}-\mathrm{C}-\mathrm{H}_{\text {o.o.p. }}+\tau \mathrm{N}-\mathrm{O}-\mathrm{C}-\mathrm{H}_{\text {o.o.p. }}^{\prime}$ \\
\hline
\end{tabular}

a Normalization constants are not given here; they are chosen as $N=\left(\Sigma c_{i}^{2}\right)^{-1 / 2}$, where $c_{i}$ are the coefficients of the individual valence coordinates; $\nu$, bond stretching; $\delta$, bending; $\gamma$, rocking; $\tau$, torsion. 
Table 6

Basis set dependence of the MP2 calculated wavenumbers $\left(\mathrm{cm}^{-1}\right)$ of the cis and trans conformers of methyl nitrite

\begin{tabular}{|c|c|c|c|c|}
\hline \multirow[t]{2}{*}{ Basis set } & \multicolumn{4}{|c|}{ Wavenumber } \\
\hline & $\nu \mathrm{N}=\mathrm{O}$ & $\nu \mathrm{C}-\mathrm{O}$ & $\delta \mathrm{O}=\mathrm{N}-\mathrm{O}$ & $\nu \mathrm{N}-\mathrm{O}$ \\
\hline \multicolumn{5}{|l|}{ Cis } \\
\hline $6-31 \mathrm{IG}$ & 1333 & 937 & 778 & 548 \\
\hline $6-311 G$ & 1333 & 946 & 782 & 587 \\
\hline $6-31++\mathrm{G}$ & 1317 & 912 & 752 & 516 \\
\hline $6-311++G$ & 1323 & 927 & 762 & 556 \\
\hline $6-31 G^{* *}$ & 1583 & 1052 & 883 & 710 \\
\hline $6-311 G^{* *}$ & 1605 & 1055 & 881 & 701 \\
\hline $6-31++\mathrm{G}^{* *}$ & 1569 & 1032 & 858 & 687 \\
\hline $6-311++G^{* *}$ & 1593 & 1041 & 864 & 682 \\
\hline \multicolumn{5}{|l|}{ Trans } \\
\hline $6-31 G$ & 1411 & 977 & 710 & 465 \\
\hline $6-311 G$ & 1404 & 988 & 725 & 486 \\
\hline $6-31++G$ & 1397 & 952 & 690 & 431 \\
\hline $6-311++G$ & 1393 & 968 & 708 & 459 \\
\hline $6-31 G^{* *}$ & 1638 & 1089 & 861 & 600 \\
\hline $6-311 G^{* *}$ & 1668 & 1104 & 854 & 595 \\
\hline $6-31++G^{* *}$ & 1623 & 1071 & 832 & 583 \\
\hline $6-311++G^{* *}$ & 1651 & 1090 & 837 & 586 \\
\hline
\end{tabular}

\subsection{Vibrational studies}

The molecule studied has 18 fundamental vibrations and the normal modes will span the irreducible representation $12 A^{\prime}+6 A^{\prime \prime}$, all vibrations being active in both the infrared and the Raman. Table 5 presents the definition of the internal symmetry coordinates used in this study.

Tables 6 and 7 show the wavenumbers and intensities of the $\nu \mathrm{N}=\mathrm{O}, \nu \mathrm{C}-\mathrm{O}, \nu \mathrm{N}-\mathrm{O}$ and $\delta \mathrm{O}=\mathrm{N}-\mathrm{O}$ fundamental modes calculated with the various basis sets used in this study (at both the HF-SCF and MP2 levels of theory). To analyze the data shown in these Tables, the PCA chemometrics method was used. This technique basically consists of rotating the original set of coordinate axes in search of directions of maximum variance [36,37]. These new directions are the principal component axes. They are obtained by a diagonalization of the covariance matrix $\boldsymbol{C}=\boldsymbol{X}^{\mathrm{t}} \boldsymbol{X}$, where $\boldsymbol{X}$ is the matrix containing the original data, usually centred on the mean and scaled to unit variance. The eigenvectors of $C$ contain the direction cosines of the PC axes with respect to the original axes. The eigenvalues
Table 7

Basis set dependence of the MP2 calculated relative intensities $(\%)$ of the cis and trans conformers of methyl nitrite

\begin{tabular}{lllll}
\hline Basis set & \multicolumn{3}{l}{ Relative intensities } & \\
\cline { 2 - 4 } & $\nu \mathrm{N}=\mathrm{O}$ & $\nu \mathrm{C}-\mathrm{O}$ & $\delta \mathrm{O}=\mathrm{N}-\mathrm{O}$ & $\nu \mathrm{N}-\mathrm{O}$ \\
\hline Cis & & & & \\
$6-31 \mathrm{G}$ & 22 & 40 & 22 & 80 \\
$6-311 \mathrm{G}$ & 20 & 44 & 22 & 65 \\
$6-31++\mathrm{G}$ & 29 & 44 & 20 & 103 \\
$6-311++\mathrm{G}$ & 25 & 44 & 21 & 80 \\
$6-31 \mathrm{G}^{* *}$ & 21 & 35 & 25 & 26 \\
$6-311 \mathrm{G}^{* *}$ & 25 & 34 & 25 & 34 \\
$6-31++\mathrm{G}^{* *}$ & 27 & 35 & 26 & 36 \\
$6-311++\mathrm{G}^{* *}$ & 29 & 34 & 26 & 41 \\
Trans & & & & \\
$6-31 \mathrm{G}$ & 32 & 20 & 100 & 67 \\
$6-311 \mathrm{G}$ & 27 & 19 & 100 & 56 \\
$6-31++\mathrm{G}$ & 38 & 20 & 100 & 89 \\
$6-311++\mathrm{G}$ & 31 & 19 & 100 & 71 \\
$6-31 \mathrm{G}^{* *}$ & 29 & 15 & 100 & 17 \\
$6-311 \mathrm{G}^{* *}$ & 34 & 15 & 100 & 25 \\
$6-31++\mathrm{G}^{* *}$ & 34 & 15 & 100 & 24 \\
$6-311++\mathrm{G}^{* *}$ & 37 & 15 & 100 & 29 \\
\hline
\end{tabular}

${ }^{a}$ Relative values to the intensity of the $\delta \mathrm{O}=\mathrm{C}-\mathrm{O}$ mode of the trans conformer.

correspond to the variance of the information content of each principal component. In performing a PCA, one projects as much as possible of the original multidimensional information into a twoor three-dimensional subspace, in the hope that any patterns present in the original data reveal themselves in this way.

In the present study, the results of a given molecular orbital calculation can be regarded as the coordinates locating the molecule in fourdimensional space, where each axis represents one vibrational mode. There are in fact two such spaces, one for the wavenumbers and another for the intensities. Each space was subjected to a separate PCA.

For the wavenumber data (centred on the mean and scaled to unit variance), the first two PA axes were found to describe $99.2 \%$ of the original information. Fig. 10 shows a plot of the molecules on the plane defined by these axes. The coordinates of the molecules on this plane are called scores, while the direction cosines of the $\mathrm{PC}$ axes with respect to 


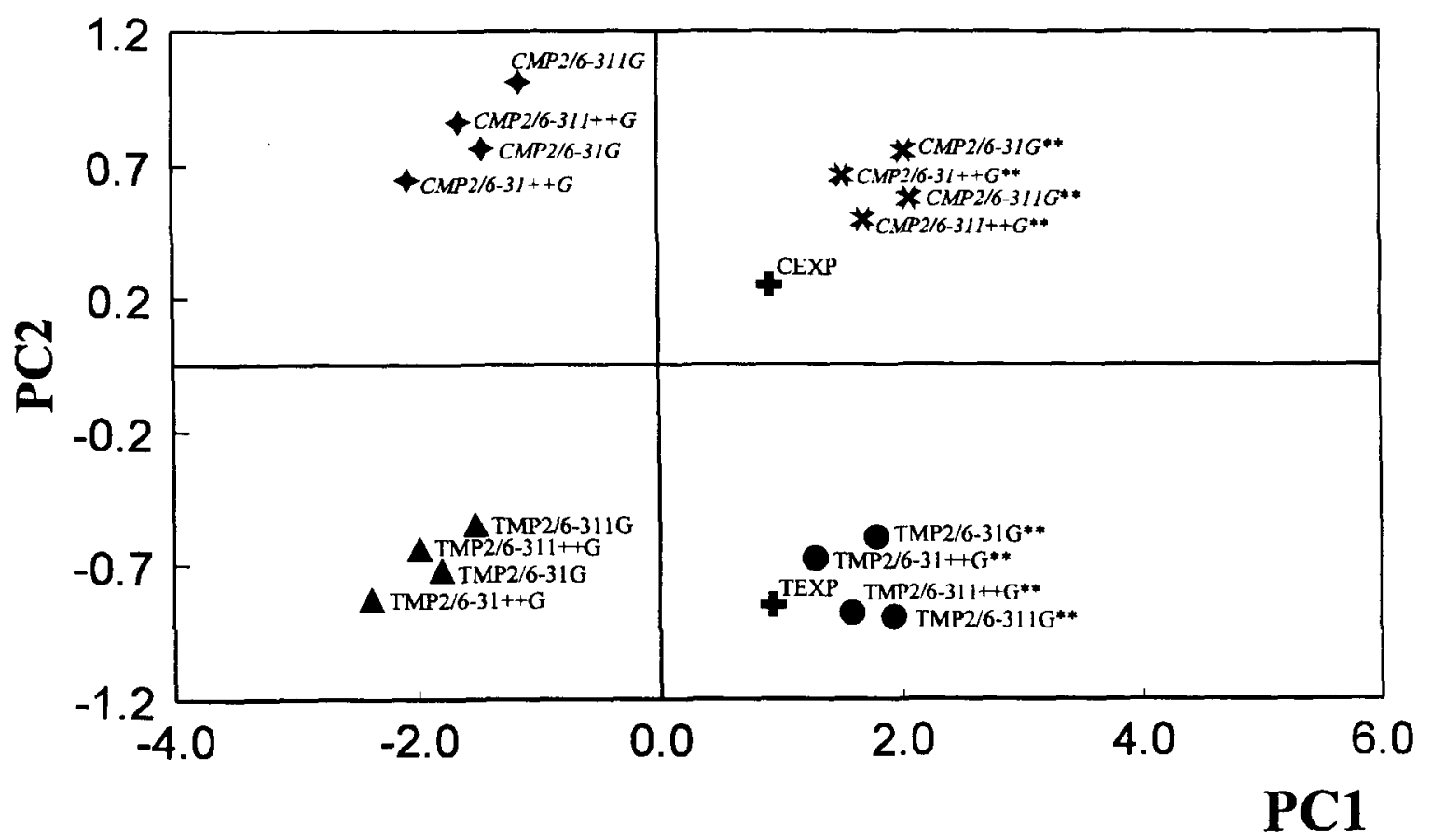

Fig. 10. Plot of the scores of the experimental and MP2 calculated molecules ( $C$, cis; $T$, trans) on the wavenumber PC axes (PC2 vs. PC1).

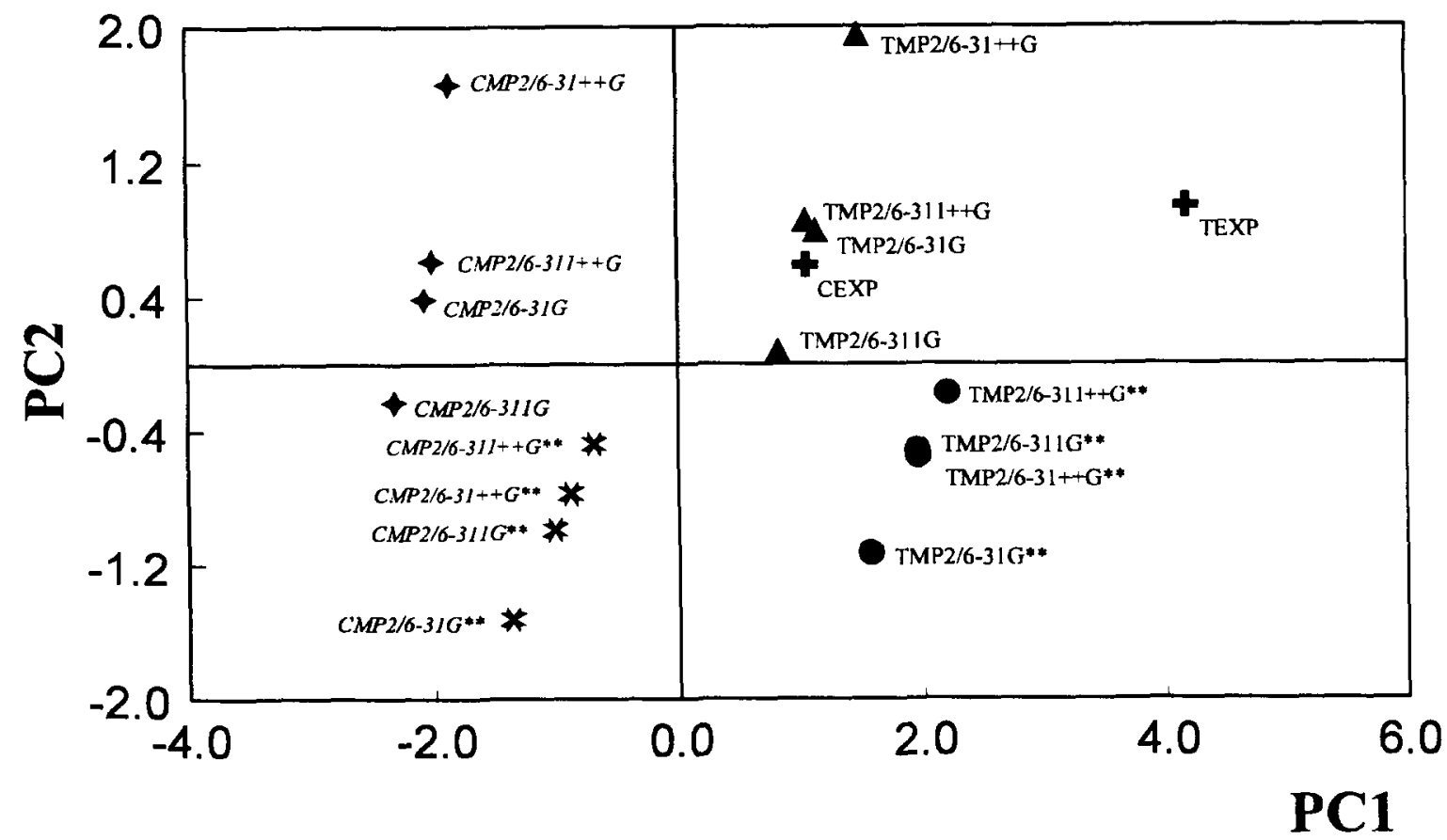

Fig. 11. Plot of the scores of the experimental and MP2 calculated molecules (C, cis; $\mathrm{T}$, trans) on the relative intensity PC axes (PC2 vs. PC1). 
Table 8

Distances between the MP2 calculated and experimental scores of wavenumbers $\left(\mathrm{cm}^{-1}\right)$ and intensities $\left(\mathrm{km} \mathrm{mol}^{-1}\right)$ of the cis and trans conformers of methyl nitrite ${ }^{\mathrm{a}}$

\begin{tabular}{|c|c|c|c|c|}
\hline \multirow[t]{3}{*}{ Basis set } & \multicolumn{4}{|c|}{ Distance } \\
\hline & \multicolumn{2}{|c|}{ Wavenumber } & \multicolumn{2}{|c|}{ Intensity } \\
\hline & Cis & Trans & Cis & Trans \\
\hline $6-31 G$ & 2.414 & 2.744 & 3.127 & 3.059 \\
\hline $6-311 G$ & 2.183 & 2.474 & 3.470 & 3.481 \\
\hline $6-31++G$ & 3.009 & 3.319 & 3.102 & 2.882 \\
\hline $6-311++G$ & 2.625 & 2.932 & 3.057 & 3.137 \\
\hline $6-31 G^{* *}$ & 1.226 & 0.887 & 3.212 & 3.338 \\
\hline $6-311 \mathrm{G}^{* *}$ & 1.211 & 1.001 & 2.599 & 2.659 \\
\hline $6-31++G^{* *}$ & 0.723 & 0.383 & 2.365 & 2.670 \\
\hline $6-311++G^{* *}$ & 0.821 & 0.651 & 2.040 & 2.723 \\
\hline
\end{tabular}

the original axes are called loadings. The first principal component $(\mathrm{PCl})$ alone describes $84.0 \%$ of the original variance, and clearly distinguishes the basis sets containing polarization functions from those that do not include such functions. A basis set containing polarization functions has a positive score on $\mathrm{PCl}$. If polarization functions are absent, the score has a negative value. The second principal component (PC2), which represents $15.2 \%$ of the variance, likewise discriminates between cis and trans geometries. The cis structure gives rise to positive scores, in contrast to the trans structure whose scores are negative.

The experimental values were also projected onto the PC axes of Fig. 10. The positive scores that these points present on $\mathrm{PCl}$ indicate that polarization functions are important for an

Table 9

Experimental and MP2 6-311G** calculated fundamental vibrational wavenumbers and IR relative intensities for methyl nitrite ${ }^{\mathrm{a}}$

\begin{tabular}{|c|c|c|c|c|c|c|c|c|}
\hline \multirow[t]{3}{*}{ Approximate description } & \multicolumn{4}{|l|}{ Calculated } & \multicolumn{4}{|c|}{ Experimental (Ar matrix) $[12,17]$} \\
\hline & \multicolumn{2}{|l|}{ Cis } & \multicolumn{2}{|l|}{ Trans } & \multicolumn{2}{|l|}{ Cis } & \multicolumn{2}{|l|}{ Trans } \\
\hline & Wavenumber & Intensity & Wavenumber & Intensity & Wavenumber & Intensity & Wavenumber & Intensity \\
\hline$\nu \mathrm{CH}_{3}$ as $A^{\prime}$ & 3236 & 2 & 3187 & 3 & 3031 & 2 & $3002^{b}$ & 1 \\
\hline$\nu \mathrm{CH}_{3}$ as. $A^{\prime \prime}$ & 3177 & 5 & 3190 & 6 & $3002^{\mathrm{b}}$ & 3 & $3002^{\mathrm{b}}$ & 3 \\
\hline$\nu \mathrm{CH}_{3} \mathrm{~s}, \quad A^{\prime}$ & 3091 & 3 & 3085 & 9 & $2952^{\mathrm{c}}$ & 2 & $2952^{c}$ & 7 \\
\hline$\nu \mathrm{N}=\mathrm{O} \quad A^{\prime}$ & 1605 & 25 & 1668 & 34 & 1613 & 47 & 1665 & 56 \\
\hline$\delta \mathrm{CH}_{3}$ as. $A^{\prime}$ & 1519 & 2 & 1536 & 1 & 1455 & 2 & 1467 & 2 \\
\hline$\delta \mathrm{CH}_{3}$ as $A^{\prime \prime}$ & 1500 & 2 & 1505 & 1 & 1438 & 3 & 1447 & 1 \\
\hline$\delta \mathrm{CH}_{3} \mathrm{~s}, \quad A^{\prime}$ & 1473 & 1 & 1487 & 2 & 1408 & 2 & 1424 & 2 \\
\hline$\gamma \mathrm{CH}_{3} \quad A^{\prime}$ & 1207 & 0.3 & 1224 & 7 & 1141 & $<1$ & 1180 & 5 \\
\hline$\gamma \mathrm{CH}_{3}$ & 1187 & 0.3 & 1195 & 0.3 & n.o. & - & 1132 & 1 \\
\hline$\nu \mathrm{C}-\mathrm{O} \quad A^{\prime}$ & 1055 & 34 & 1104 & 15 & 994 & 32 & 1043 & 12 \\
\hline$\delta \mathrm{O}=\mathrm{N}-\mathrm{O} A^{\prime}$ & 881 & 25 & 854 & 100 & 838 & 20 & 807 & 100 \\
\hline$\nu \mathrm{N}-\mathrm{O} \quad A^{\prime}$ & 701 & 34 & 595 & 25 & 625 & 37 & 565 & 24 \\
\hline$\delta \mathrm{N}-\mathrm{O}-\mathrm{C} A^{\prime}$ & 369 & 0.4 & 384 & 3 & $351^{d}$ & 2 & 370 & 4 \\
\hline$\tau \mathrm{N}-\mathrm{O} \quad A^{\prime \prime}$ & 370 & 0.5 & 233 & 0.2 & $351^{\mathrm{d}}$ & 2 & $213^{\mathrm{e}}$ & \\
\hline$\tau \mathrm{C}-\mathrm{O} \quad A^{\prime \prime}$ & 226 & 0.05 & 92 & 0.1 & $186^{\mathrm{e}}$ & & $105^{f}(?)$ & \\
\hline
\end{tabular}

${ }^{a}$ Wavenumbers in $\mathrm{cm}^{-1}$. Relative intensities were normalized intensities to the most intense band at $807 \mathrm{~cm}^{-1} ; \nu$, bond stretching; $\delta$, bending; $\gamma$, rocking; $\tau$, torsion; n.o., not observed; (?), tentative assignment. See Table 5 for definition of symmetry coordinates.

${ }^{b}$ This band has partial contributions from the $\nu \mathrm{CH}_{3}$ as. $A^{\prime \prime}$ mode of both conformers and also from the $\nu \mathrm{CH}_{3}$ as. $A^{\prime}$ mode of the trans form; its total experimental relative intensity (7) was divided into partial contributions with intensity ratios equal to the ratios between the correspondent calculated partial intensities.

c This band has partial contributions from the $\nu \mathrm{CH}_{3}$ s. mode of both conformers; its total experimental relative intensity (9) was divided into partial contributions with intensity ratios equal to the ratios between the correspondent calculated partial intensities.

${ }^{d}$ This band has partial contributions from both the $\delta \mathrm{N}-\mathrm{O}-\mathrm{C}$ and $\tau \mathrm{N}-\mathrm{O}$ modes of the cis form; its total experimental relative intensity

(4) was divided into partial contributions with intensity ratios equal to the ratios between the correspondent calculated partial intensities.

${ }^{\text {e }}$ Gas-phase value [17]; relative intensity not reported.

${ }^{f}$ Solid [18]; relative intensity not reported. 
adequate description of the vibrational modes of $\mathrm{CH}_{3} \mathrm{ONO}$ considered here.

In the case of intensities, the first two PC axes were found to describe $93.6 \%$ of the original variance. The plot of the scores of $\mathrm{PCl}$ and $\mathrm{PC} 2$ is shown in Fig. 11. In this case, PCl, with $69.3 \%$ of the original information, clearly distinguishes between the cis and trans forms. The calculated trans structures have positive scores, whereas the calculated cis structures have negative scores. PC2, with $24.3 \%$ of the original variance, separates those basis sets containing polarization functions from those that do not include such functions. Except in the case of the MP2 6-311G calculation for the cis conformer, all calculations involving polarization functions have a negative score on PC2, whereas those calculations without polarization functions have positive scores.

The projection of the experimental values for each conformer in Fig. 11 shows that the obtained points are not as close to a particular group of calculated results having the same configuration as in the case of the data relative to wavenumbers. However, an analysis of the distances, calculated by the following expression
$D=\left[\sum\left(\text { calc }_{\mathrm{i}}-\exp _{\mathrm{i}}\right)^{2}\right]^{1 / 2}$

and presented in Table 8 , reveals that as for the wavenumbers the intensities are better described by wavefunctions containing polarization functions.

The MP2 6-311G** calculated fundamental wavenumbers and infrared intensities for the nonisotopically substituted compound are compared with the experimental data $[12,17,18]$ in Table 9 , and a schematic representation of both calculated and experimental infrared spectra is drawn in Fig. 12. The calculated potential energy distributions (PEDs) are shown in Table 10. Tables 11 and 12 present the calculated and experimental infrared data for the $\mathrm{CD}_{3} \mathrm{ONO}$ species and the corresponding calculated PED, respectively.

As can be easily noted by looking at Fig. 12, the MP2 6-311G** calculated results (both wavenumbers and intensities) for $\mathrm{CH}_{3} \mathrm{ONO}$ agree very well with the experimental data $[12,17,18]$. The following points deserve special comments.

(i) As could be expected, the calculated wavenumbers show a systematic overestimation. However, when compared with the HF-SCF calculated

Table 10

MP2 6-311G** potential energy distribution (PED) for cis- and trans-methyl nitrite

\begin{tabular}{|c|c|c|c|c|}
\hline \multirow{2}{*}{$\begin{array}{l}\text { Approximate } \\
\text { description }\end{array}$} & \multicolumn{2}{|l|}{ Cis } & \multicolumn{2}{|l|}{ Trans } \\
\hline & Wavenumber & PED $^{b}$ & Wavenumber & $\mathrm{PED}^{\mathrm{b}}$ \\
\hline$\nu \mathrm{CH}_{3}$ as. $A^{\prime}$ & 3236 & $S_{4}[96]$ & 3187 & $S_{5}[100]$ \\
\hline$\nu \mathrm{CH}_{3}$ as. $A^{\prime \prime}$ & 3177 & $S_{5}[100]$ & 3190 & $S_{4}[100]$ \\
\hline$\nu \mathrm{CH}_{3}$ s. $\quad A^{\prime}$ & 3091 & $S_{6}[97]+S_{4}[5]$ & 3085 & $S_{6}[100]$ \\
\hline$\nu \mathrm{N}=\mathrm{O} \quad A^{\prime}$ & 1605 & $S_{1}[96]+S_{7}[6]$ & 1668 & $S_{1}[96]+S_{7}[5]$ \\
\hline$\delta \mathrm{CH}_{3}$ as. $A^{\prime}$ & 1519 & $S_{9}[70]+S_{11}[15]+S_{12}[11]$ & 1536 & $S_{9}[84]+S_{11}[10]+S_{12}[8]$ \\
\hline$\delta \mathrm{CH}_{3}$ as. $A^{\prime \prime}$ & 1500 & $S_{10}[99]+S_{13}[7]$ & 1505 & $S_{10}[98]+S_{13}[9]$ \\
\hline$\delta \mathrm{CH}_{3}$ s. $\quad A^{\prime}$ & 1473 & $S_{11}[84]+S_{9}[12]$ & 1487 & $S_{11}[94]+S_{9}[10]$ \\
\hline$\gamma \mathrm{CH}_{3} \quad A^{\prime}$ & 1207 & $S_{12}[70]+S_{8}[10]+S_{9}[9]+S_{7}[6]$ & 1224 & $S_{12}[80]+S_{9}[7]+S_{8}[5]$ \\
\hline$\gamma \mathrm{CH}_{3}$ & 1187 & $S_{13}[89]+S_{10}[7]$ & 1195 & $S_{13}[97]+S_{10}[5]$ \\
\hline$\nu \mathrm{C}-\mathrm{O} \quad A^{\prime}$ & $1055^{c}$ & $S_{3}[82]+S_{7}[22]+S_{2}[12]+S_{12}[6]$ & $1104^{\mathrm{c}}$ & $S_{3}[90]+S_{7}[17]$ \\
\hline$\delta \mathrm{O}=\mathrm{N}-\mathrm{O} A^{\prime}$ & 881 & $S_{7}[44]+S_{2}[30]+S_{3}[25]+S_{1}[6]$ & $854^{\circ}$ & $S_{7}[44]+S_{2}[51]+S_{3}[17]+S_{1}[15]+S_{12}[6]$ \\
\hline$\nu \mathrm{N}-\mathrm{O} \quad A^{\prime}$ & $701^{c}$ & $S_{2}[86]+S_{8}[28]+S_{7}[10]+S_{12}[7]$ & 595 & $S_{2}[69]+S_{7}[14]$ \\
\hline$\delta \mathrm{N}-\mathrm{O}-\mathrm{C} \quad A^{\prime}$ & $369^{c}$ & $S_{8}[65]+S_{7}[16]$ & $384^{\mathrm{c}}$ & $S_{8}[93]+S_{7}[23]$ \\
\hline$\tau \mathrm{N}-\mathrm{O} \quad A^{\prime \prime}$ & $370^{\mathrm{c}}$ & $S_{14}[111]+S_{15}[10]+S_{13}[6]$ & 233 & $S_{14}[88]+S_{13}[6]$ \\
\hline$\tau \mathrm{C}-\mathrm{O}$ & 226 & $S_{15}[106]$ & 92 & $S_{15}[105]$ \\
\hline
\end{tabular}

${ }^{a}$ Wavenumbers in $\mathrm{cm}^{-1} . \nu$, bond stretching; $\delta$, bending; $\gamma$, rocking; $\tau$, torsion. See Table 5 for definition of symmetry coordinates.

${ }^{\mathrm{b}}$ Only PED values larger than $5 \%$ are presented.

${ }^{c}$ This mode has a considerable contribution ( $>10 \%$ ) from the coupling force constants (non-diagonal terms) to its PED. 
(a)

Experimental (IR-Argon Matrix [12,17])
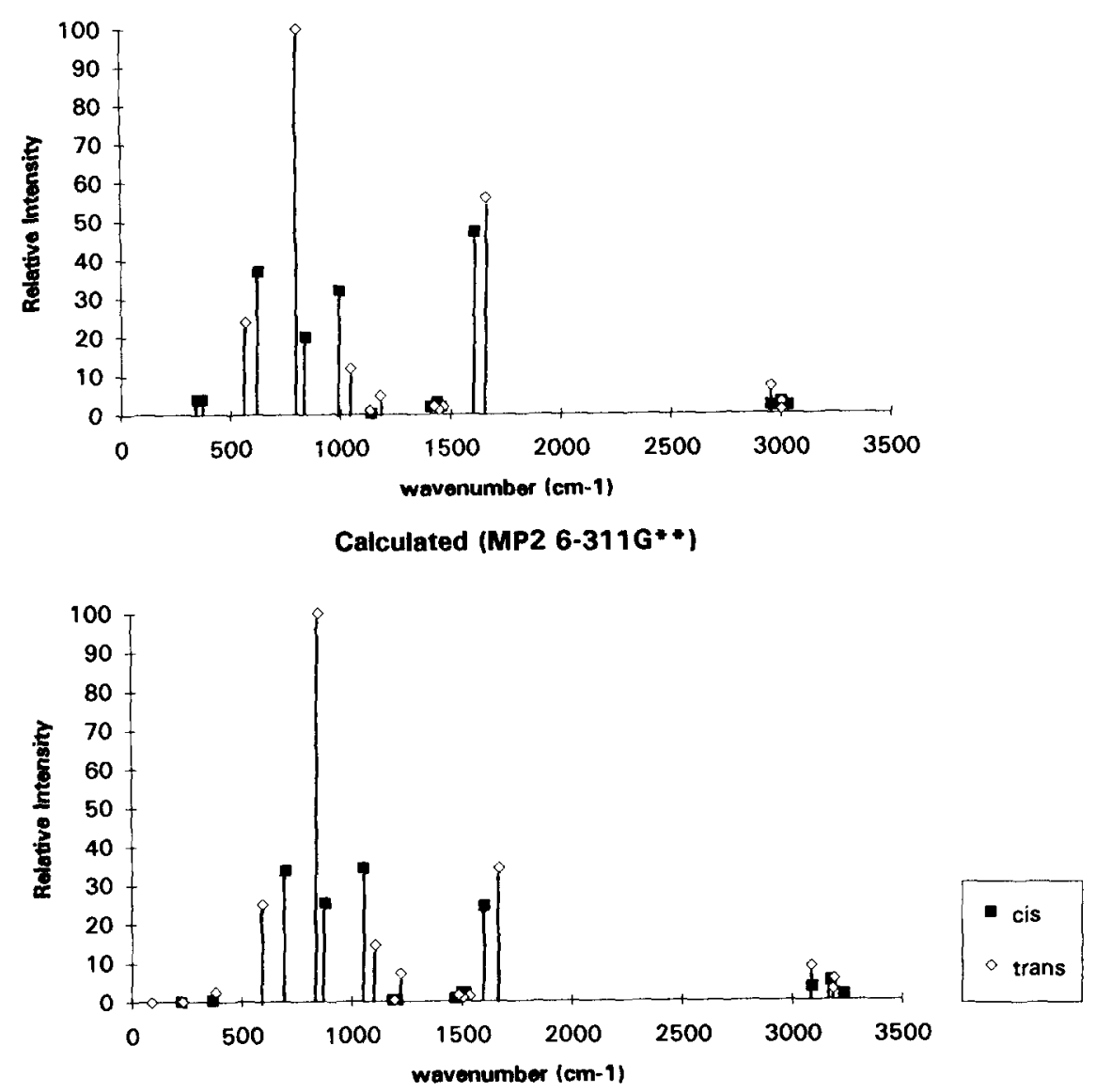

Fig. 12. (a) Experimental (in Argon matrix $[12,17]$ ) and MP2 6-311G** calculated infrared spectra of methyl nitrite. (b) Scale expansion of the $\delta \mathrm{CH}_{3}$ spectral region. (c) Scale expansion of the $\nu \mathrm{CH}_{3}$ spectral region.

values $\left(6-311 \mathrm{G}^{* *}\right)$ the results obtained at the MP2 level are strongly improved. For example, for the cis conformer, $\nu \mathrm{CH}_{3}$ s. reduces from 3207 to $3091 \mathrm{~cm}^{-1}, \nu \mathrm{N}=\mathrm{O}$ from 1951 to $1605 \mathrm{~cm}^{-1}, \nu \mathrm{C}-$ $\mathrm{O}$ from 1217 to $1055 \mathrm{~cm}^{-1}$, and $\delta \mathrm{NOC}$ from 396 to $369 \mathrm{~cm}^{-1}$.

(ii) The present assignments show general agreement with those previously made $[12,18]$. However, the calculations show that the $\nu \mathrm{CH}_{3}$ as. $A^{\prime \prime}$ stretching mode in the trans form should occur at a slightly higher wavenumber than the $\nu \mathrm{CH}_{3}$ as. $A^{\prime}$ mode, both modes appearing at a wavenumber similar to that of the $\nu \mathrm{CH}_{3}$ as. $A^{\prime}$ mode of the cis conformer; the assignment of the experimental bands in this spectral region was then changed in agreement with these results. In addition, the $\mathrm{CH}_{3}$ rocking vibrations are now reassigned in a slightly different way. Thus, the most intense band at $1180 \mathrm{~cm}^{-1}$ is reassigned to the $\gamma \mathrm{CH}_{3} A^{\prime}$ mode of the trans form (in agreement with the assignments of Ref. [12], but in disagreement with the most recent assignment made in Ref. [18]), and the band at $1141 \mathrm{~cm}^{-1}$ is assigned to the same mode in the cis conformer (this band was assigned previously [18] to the $\gamma \mathrm{CH}_{3} A^{\prime \prime}$ mode in both conformers, although it had been shown earlier [12] that it 
(b)

Experimental (IR-Argon Matrix [12,17])
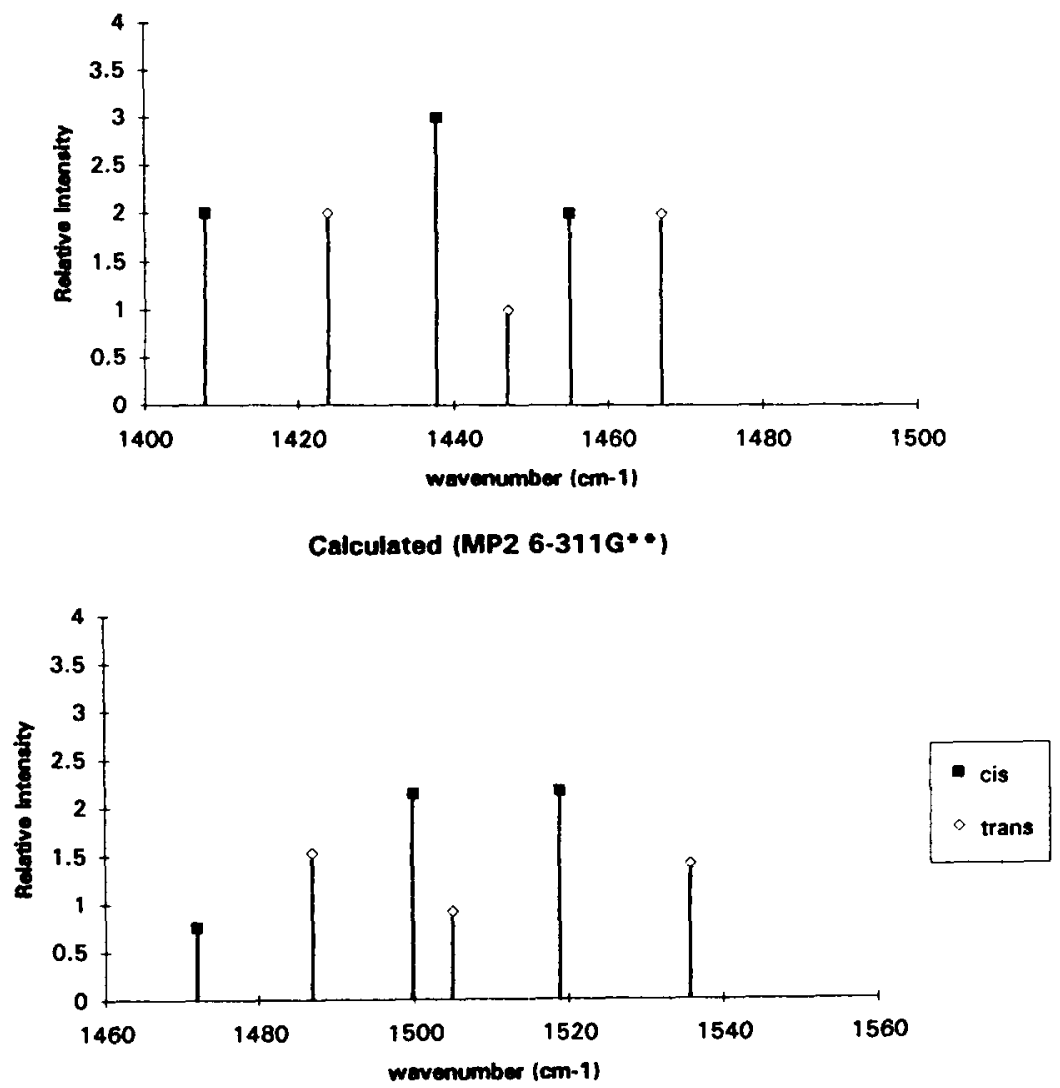

Fig. 12. Continued.

should originate only in the cis form). Finally, the calculations indicate that the $\tau \mathrm{N}-\mathrm{O}$ torsion in the cis conformer should occur at a wavenumber close to that of the $\delta$ NOC bending vibration ( $\approx 370 \mathrm{~cm}^{-1}$, calculated values). Thus, we assigned both modes to the band at $351 \mathrm{~cm}^{-1}$, previously assigned only to the bending vibration. Indeed, the earlier assignment of the $\tau \mathrm{N}-\mathrm{O}$ mode to the band at $249 \mathrm{~cm}^{-1}$ (gas phase [18]) is not supported by the calculations, and the gas-phase infrared bands appearing either at $377 \mathrm{~cm}^{-1}$ or $327 \mathrm{~cm}^{-1}$ [18] seem better candidates to be ascribed to this mode than the $249 \mathrm{~cm}^{-1}$ band. In the trans form, $\delta \mathrm{NOC}$ is predicted to occur at a higher frequency (calc. $384 \mathrm{~cm}^{-1}$ ) and is assigned to the $370 \mathrm{~cm}^{-1}$ experimental band, while the torsional mode is predicted to occur at a much lower wavenumber (calc.
$233 \mathrm{~cm}^{-1}$ ) and is assigned to the experimentally observed band at $213 \mathrm{~cm}^{-1}$ (gas phase [17]).

(iii) The normal mode analysis carried out using HF-SCF calculated force constants, at the 4-21G [20], 3-21G [18] or even $6-311 \mathrm{G}^{* *}$ (this study) level, predicts the $\nu \mathrm{N}-\mathrm{O}$ and $\delta \mathrm{O}=\mathrm{N}-\mathrm{O}$ coordinates to be considerably coupled in both conformers, giving rise to two normal modes with important contributions from these two coordinates; the mode having the higher wavenumber has a predominant contribution from the $\nu \mathrm{N}-\mathrm{O}$ coordinate, whilst that appearing at a lower wavenumber has a predominant contribution from the $\delta \mathrm{O}=\mathrm{N}-\mathrm{O}$ oscillator. However, the picture obtained when the highest level MP2 6-311G** calculations are considered is completely different. In both forms, only one normal mode shows a high degree of mixing of 


\section{(c)}

Experimental (IR-Argon Matrix [12,17])
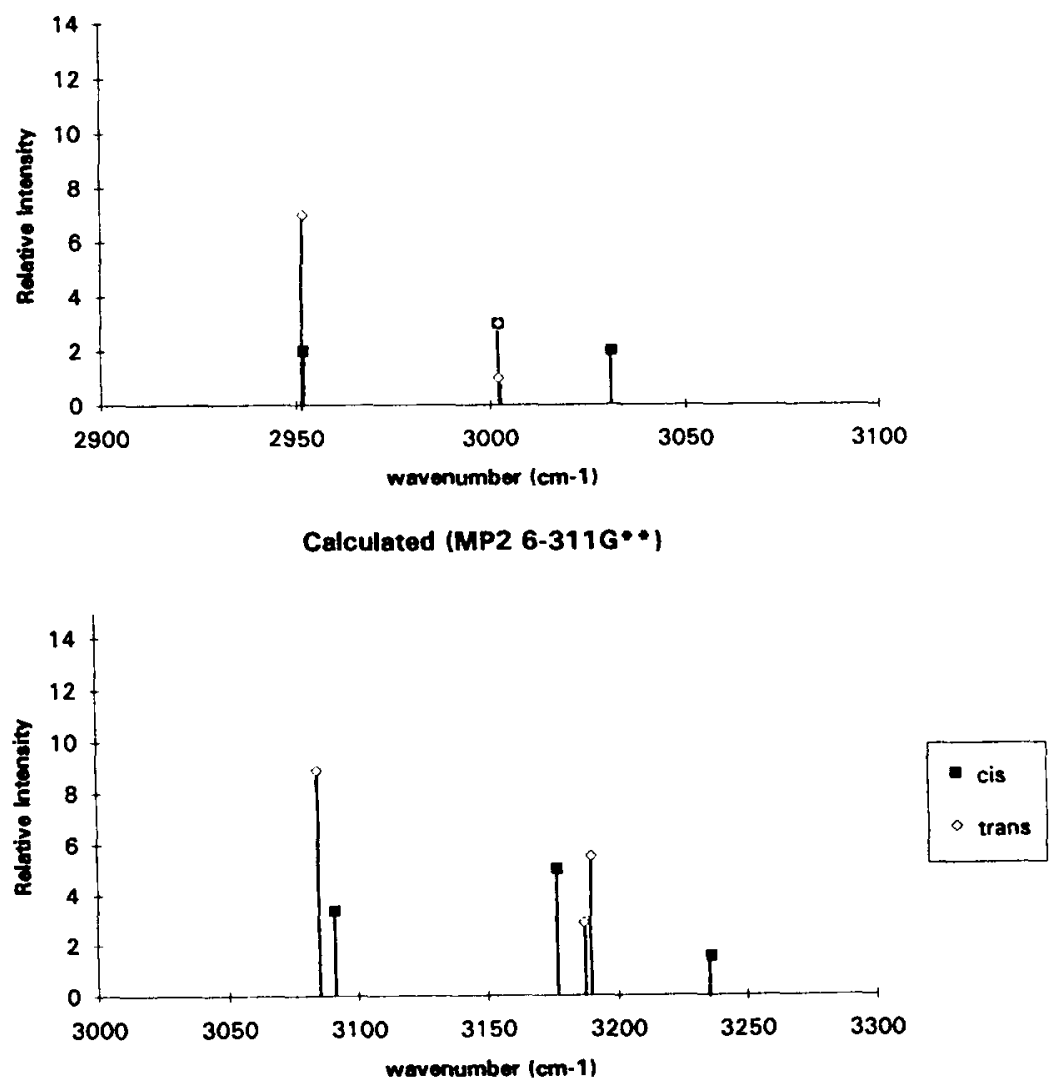

Fig. 12. Continued.

the $\nu \mathrm{N}-\mathrm{O}$ and $\delta \mathrm{O}=\mathrm{N}-\mathrm{O}$ coordinates (calculated wavenumber in cis is $881 \mathrm{~cm}^{-1}$; and in trans is $854 \mathrm{~cm}^{-1}$; see Table 10). This vibration should be approximately described as the $\delta \mathrm{O}=\mathrm{N}-\mathrm{O}$ bending mode, since the $\nu \mathrm{N}-\mathrm{O}$ coordinate has a strongly predominating contribution to a different normal mode (calculated wavenumber in cis is $701 \mathrm{~cm}^{-1}$; and in trans is $595 \mathrm{~cm}^{-1}$; see Table 10). Thus, these results clearly indicate that the previous assignments of the $\nu \mathrm{N}-\mathrm{O}$ and $\delta \mathrm{O}=\mathrm{N}-\mathrm{O}$ modes to the experimentally observed bands $[12,17,18]$ should be reversed.

(iv) A good correlation can be established between the wavenumbers corresponding to the stretching vibrations $(\nu \mathrm{N}=\mathrm{O}, \nu \mathrm{N}-\mathrm{O}$ and $\nu \mathrm{C}-\mathrm{O})$ and the correspondent bond lengths (Table 13); the shorter the bond (i.e. the stronger the bond and the larger the associated force constant), the greater the wavenumber.

(v) The calculated intensities are in remarkable agreement with the experimental results. Only the relative intensity of the $\nu \mathrm{N}=\mathrm{O}$ stretching mode in both conformers is significantly underestimated by the calculations. However, it should be noted that the experimental intensity data available were obtained for the molecule isolated in an Ar matrix [12]. Although large intensity differences when compared with the gas-phase data are not expected to occur for the vast majority of bands, the bands associated with the $\nu \mathrm{N}=\mathrm{O}$ normal mode are those which could be expected to be more significantly affected by matrix-substrate interactions, due to the greater polarizability of the double bond. 
Table 11

Experimental and MP2 6-311G** calculated fundamental vibrational wavenumbers and calculated IR relative intensities for methyl nitrite- $d_{3}{ }^{\mathrm{a}}$

\begin{tabular}{|c|c|c|c|c|c|c|c|}
\hline \multirow{3}{*}{$\begin{array}{l}\text { Approximate } \\
\text { description }\end{array}$} & & \multicolumn{4}{|l|}{ Calculated } & \multicolumn{2}{|c|}{ Experimental (Ar matrix) [13] } \\
\hline & & \multicolumn{2}{|l|}{ Cis } & \multicolumn{2}{|l|}{ Trans } & \multirow{2}{*}{$\begin{array}{l}\text { Cis } \\
\text { Wavenumber }\end{array}$} & \multirow{2}{*}{$\begin{array}{l}\text { Trans } \\
\text { Wavenumber }\end{array}$} \\
\hline & & Wavenumber & Intensity & Wavenumber & Intensity & & \\
\hline$\nu \mathrm{CD}_{3}$ as & $A^{\prime}$ & 2402 & 2 & 2365 & 3 & 2279 & $2262^{c}$ \\
\hline$\nu \mathrm{CD}_{3}$ as & $A^{\prime \prime}$ & 2358 & 5 & 2370 & 6 & 2256 & $2262^{\mathrm{c}}$ \\
\hline$\nu \mathrm{CD}_{3} \mathrm{~s}$ & $A^{\prime}$ & 2214 & 4 & 2209 & 10 & 2126 & $2114^{d}$ \\
\hline$\nu \mathrm{N}=\mathrm{O}$ & $A^{\prime}$ & 1601 & 41 & 1667 & 57 & 1616 & 1667 \\
\hline$\delta \mathrm{CD}_{3} \mathrm{~s}$ & $A^{\prime}$ & 1144 & 1 & 1173 & 7 & 1093 & 1115 \\
\hline$\delta \mathrm{CD}_{3}$ as. & $A^{\prime}$ & 1089 & 3 & 1107 & 0.06 & $1055^{\mathrm{e}}$ & n.o. \\
\hline$\delta \mathrm{CD}_{3}$ as & $A^{\prime \prime}$ & 1084 & 1 & 1088 & 0.4 & 1049 & $1055^{e}$ \\
\hline$\nu \mathrm{C}-\mathrm{O}$ & $A^{\prime}$ & 1077 & 28 & 1050 & 7 & 1028 & 1020 \\
\hline$\gamma \mathrm{CD}_{3}$ & $A^{\prime}$ & 960 & 41 & 995 & 87 & 912 & 949 \\
\hline$\gamma \mathrm{CD}_{3}$ & $A^{\prime \prime}$ & 928 & 1 & 919 & 1 & $895^{f}$ & $895^{\mathrm{f}}$ \\
\hline$\delta \mathrm{O}=\mathrm{N}-\mathrm{O}$ & $A^{\prime}$ & 838 & 46 & 813 & 100 & 799 & 777 \\
\hline$\nu \mathrm{N}-\mathrm{O}$ & $A^{\prime}$ & 657 & 33 & 577 & 37 & 596 & 552 \\
\hline$\delta \mathrm{N}-\mathrm{O}-\mathrm{C}$ & $A^{\prime}$ & 338 & 0.6 & 352 & 4 & $304^{\mathrm{g}}$ & $333^{\mathrm{g}}$ \\
\hline$\tau \mathrm{N}-\mathrm{O}$ & $A^{\prime \prime}$ & 355 & 0.5 & 222 & 0.1 & $333^{\mathrm{g}}$ & $205^{\mathrm{g}}$ \\
\hline$\tau \mathrm{C}-\mathrm{O}$ & $A^{\prime \prime}$ & 165 & 0.06 & 74 & 0.2 & $140^{\mathrm{g}}$ & $80^{\mathrm{h}}(?)$ \\
\hline
\end{tabular}

${ }^{a}$ Wavenumbers in $\mathrm{cm}^{-1}$. Relative intensities were normalized intensities to the most intense band at $813 \mathrm{~cm}^{-1} ; \nu$, bond stretching; $\delta$, bending; $\gamma$, rocking; $\tau$, torsion; n.o., not observed; (?), tentative assignment. See Table 5 for definition of symmetry coordinates.

${ }^{\mathrm{b}}$ Experimental intensities not reported.

' This band is assigned to both the $\nu \mathrm{CD}_{3}$ as. $A^{\prime}$ and $A^{\prime \prime}$ modes of the trans conformer

${ }^{d}$ A different assignment is also possible for this mode. It can be assigned to the bands at 2083 and $2192 \mathrm{~cm}^{-1}$, which may be a Fermi doublet (gravity centre $\approx 2115 \mathrm{~cm}^{-1}$ ) resulting from the interaction between the $\nu \mathrm{CD}_{3}$ s. fundamental and the first overtone of the $\delta \mathrm{CD}_{3}$ s. or $\delta \mathrm{CD}_{3}$ as. $A^{\prime}$ vibration.

' $T$ his band is assigned to both the $\delta \mathrm{CD}_{3}$ as. $A^{\prime}$ vibration of the cis form and $\delta \mathrm{CD}_{3}$ as. $A^{\prime \prime}$ mode of the trans conformer.

"This band is assigned to $\delta \mathrm{CD}_{3} A$ " in both forms.

${ }^{g}$ Gas-phase value [18].

${ }^{\text {h }}$ Solid [18].

The MP2 6-311G** vibrational results obtained for some isotopically substituted compounds $\left({ }^{13} \mathrm{CH}_{3} \mathrm{ONO}, \mathrm{CH}_{3} \mathrm{O}^{15} \mathrm{NO}\right.$ and, in particular, $\mathrm{CD}_{3} \mathrm{ONO}$ - Tables 11 and 12) reinforce the validity of our assignments made for the nonisotopically substituted species. The excellent performance of the MP2 6-311G** calculations with respect to the wavenumber shifts associated with isotopic labelling is clearly shown in Table 14, where calculated and experimental wavenumbers (and wavenumber shifts) for the $\nu \mathrm{N}=\mathrm{O}, \nu \mathrm{N}-\mathrm{O}$ and $\delta \mathrm{O}=\mathrm{N}-\mathrm{O}$ modes are shown.

Owing to the lack of detailed experimental data for all the above isotopically substituted compounds except $\mathrm{CD}_{3} \mathrm{ONO}$ [13], the infrared vibrational spectra of these molecules are not discussed in detail here.
However, full data (wavenumbers and PEDS) for ${ }^{13} \mathrm{CH}_{3} \mathrm{ONO}$ and $\mathrm{CH}_{3} \mathrm{O}^{15} \mathrm{NO}$ may be obtained from the authors upon request. With respect to the $\mathrm{CD}_{3} \mathrm{ONO}$ species, the following points must be stressed.

(i) When compared with the experimental data, the calculated wavenumbers show a general overestimation similar to that observed for the non-isotopically substituted molecule. In addition, although the experimental intensities have still not been reported in quantitative terms [13,18], the calculated intensities also show good qualitative agreement with the relative intensities of the bands in Fig. 4 of Ref. [13]. Moreover, also as in the normal species, the approximately described $\delta \mathrm{O}=\mathrm{N}-\mathrm{O}$ mode appears at a higher wavenumber than $\nu \mathrm{N}-\mathrm{O}$ (see Table 12). 
Table 12

MP2 6-311G** potential energy distribution (PED) for cis- and trans-methyl nitrite- $d_{3}{ }^{\mathrm{a}}$

\begin{tabular}{|c|c|c|c|c|}
\hline \multirow{2}{*}{$\begin{array}{l}\text { Approximate } \\
\text { description }\end{array}$} & \multicolumn{2}{|l|}{ Cis } & \multicolumn{2}{|l|}{ Trans } \\
\hline & Wavenumber & $\mathrm{PED}^{\mathrm{b}}$ & Wavenumber & PED $^{b}$ \\
\hline$\nu \mathrm{CD}_{3}$ as. $A^{\prime}$ & 2402 & $S_{4}[99]$ & 2365 & $S_{5}[100]$ \\
\hline$\nu \mathrm{CD}_{3}$ as. $A^{\prime \prime}$ & 2358 & $S_{5}[100]$ & 2370 & $S_{4}[100]$ \\
\hline$\nu \mathrm{CD}_{3}$ s. $\quad A^{\prime}$ & 2214 & $S_{6}[99]$ & 2209 & $S_{6}[100]$ \\
\hline$\nu \mathrm{N}=\mathrm{O} \quad A^{\prime}$ & 1601 & $S_{1}[99]+S_{7}[7]$ & 1667 & $S_{1}[97]+S_{7}[5]$ \\
\hline$\delta \mathrm{CD}_{3}$ s. $\quad A^{\prime}$ & $1144^{\mathrm{c}}$ & $S_{11}[97]+S_{3}[23]$ & $1173^{\mathrm{c}}$ & $S_{11}[75]+S_{3}[49]+S_{7}[6]$ \\
\hline$\delta \mathrm{CD}_{3}$ as. $A^{\prime}$ & 1089 & $S_{9}[87]$ & 1107 & $S_{9}[94]$ \\
\hline$\delta \mathrm{CD}_{3}$ as. $A^{\prime \prime}$ & 1084 & $S_{10}[104]$ & 1088 & $S_{10}[102]$ \\
\hline$\nu \mathrm{C}-\mathrm{O} \quad A^{\prime}$ & $1077^{\mathrm{c}}$ & $S_{3}[39]+S_{7}[37]+S_{8}[16]+S_{12}[13]+S_{2}[6]$ & 1050 & $S_{3}[26]+S_{11}[30]+S_{7}[16]+S_{12}[7]+S_{8}[7]$ \\
\hline$\gamma \mathrm{CD}_{3}$ & 960 & $S_{12}[50]+S_{3}[27]+S_{2}[20]+S_{8}[6]$ & 995 & $S_{12}[56]+S_{2}[21]+S_{3}[19]+S_{1}[6]$ \\
\hline$\gamma \mathrm{CD}_{3} \quad A^{\prime \prime}$ & 928 & $S_{13}[90]$ & 919 & $S_{13}[104]$ \\
\hline$\delta \mathrm{O}=\mathrm{N}-\mathrm{O} \quad A^{\prime}$ & 838 & $\begin{array}{l}S_{7}[33]+S_{2}[35]+S_{3}[21]+S_{11}[7]+S_{12}[6] \\
+S_{1}[6]\end{array}$ & $813^{\mathrm{c}}$ & $S_{7}[41]+S_{2}[35]+S_{12}[28]+S_{3}[12]+S_{1}[9]$ \\
\hline$\nu \mathrm{N}-\mathrm{O} \quad A^{\prime}$ & $657^{\mathrm{c}}$ & $S_{2}[67]+S_{12}[23]+S_{8}[16]+S_{7}[15]$ & 577 & $S_{2}[66]+S_{7}[14]+S_{3}[5]$ \\
\hline$\delta \mathrm{N}-\mathrm{O}-\mathrm{C} \quad A^{\prime}$ & $338^{\mathrm{c}}$ & $S_{8}[69]+S_{7}[14]$ & $352^{\mathrm{c}}$ & $S_{8}[90]+S_{7}[20]+S_{12}[7]$ \\
\hline$\tau \mathrm{N}-\mathrm{O} \quad A^{\prime \prime}$ & $355^{\mathrm{c}}$ & $S_{14}[113]+S_{15}[11]+S_{13}[9]$ & 222 & $S_{14}[90]+S_{13}[7]$ \\
\hline$\tau \mathrm{C}-\mathrm{O}$ & 165 & $S_{15}[105]$ & $74^{\mathrm{c}}$ & $S_{15}[110]$ \\
\hline
\end{tabular}

${ }^{a}$ Wavenumbers in $\mathrm{cm}^{-1} ; \nu$, bond stretching; $\delta$, bending; $\gamma$, rocking; $\tau$, torsion. See Table 5 for definition of symmetry coordinates.

${ }^{\mathrm{b}}$ Only PED values larger than $5 \%$ are presented.

${ }^{c}$ This mode has a considerable contribution ( $>10 \%$ ) from the coupling force constants (non-diagonal terms) to its PED.

Table 13

Experimental and MP2 6-311G** calculated $\mathrm{N}=\mathrm{O}, \mathrm{N}-\mathrm{O}$ and $\mathrm{C}-\mathrm{O}$ bond lengths, and $\nu \mathrm{N}=\mathrm{O}, \nu \mathrm{N}-\mathrm{O}$ and $\nu \mathrm{C}-\mathrm{O}$ vibrational wavenumbers of methyl nitrite

\begin{tabular}{|c|c|c|c|c|c|c|c|c|c|c|c|c|}
\hline \multirow[t]{2}{*}{ Conformer } & \multicolumn{2}{|l|}{$\mathrm{N}=\mathrm{O}$} & \multirow[t]{2}{*}{$\nu \mathrm{N}=\mathrm{O}^{\exp }$} & \multirow[t]{2}{*}{$\nu \mathrm{N}=\mathrm{O}^{\text {calc. }}$} & \multicolumn{2}{|l|}{$\mathrm{N}-\mathrm{O}$} & \multirow[t]{2}{*}{$\nu \mathrm{N}-\mathrm{O}^{\exp }$} & \multirow[t]{2}{*}{$\nu \mathrm{N}-\mathrm{O}^{\text {calc. }}$} & \multicolumn{2}{|l|}{$\mathrm{C}-\mathrm{O}$} & \multirow[t]{2}{*}{$\nu \mathrm{C}-\mathrm{O}^{\exp }$} & \multirow[t]{2}{*}{$\nu \mathrm{C}-\mathrm{O}^{\text {calc }}$} \\
\hline & Exp. & Calc. & & & Exp. & Calc. & & & Exp. & Calc. & & \\
\hline Cis & 1.182 & 1.194 & 1613 & 1605 & 1.394 & 1.389 & 625 & 701 & 1.436 & 1.434 & 994 & 1055 \\
\hline Trans & 1.164 & 1.182 & 1665 & 1668 & 1.415 & 1.415 & 595 & 565 & 1.436 & 1.429 & 1043 & 1104 \\
\hline
\end{tabular}

${ }^{a}$ Wavenumbers in $\mathrm{cm}^{-1}$; bond lengths in $\AA$; experimental data taken from Refs. [12] and [32].

(ii) The assignments made here do not differ very much from the previous ones [13,17], although several important exceptions must be noted. (a) The $\gamma \mathrm{CD}_{3} A^{\prime}$ mode in both conformers is predicted to correspond to a band having a large intensity, while the $\gamma \mathrm{CD}_{3} A^{\prime \prime}$ mode is predicted to give rise to a low intensity infrared band. Thus, these modes are reassigned in such a way that the two intense bands at 949 and $912 \mathrm{~cm}^{-1}$ are ascribed to the $\gamma \mathrm{CD}_{3} A^{\prime}$ modes of the trans and cis forms, respectively (calculated: 995 and $960 \mathrm{~cm}^{-1}$ ), and the $\gamma \mathrm{CD}_{3} A^{\prime \prime}$ vibration in both forms (calculated: $928 \mathrm{~cm}^{-1}$ cis; $919 \mathrm{~cm}^{-1}$ trans) to the low intensity band appearing at $985 \mathrm{~cm}^{-1}$, previously assigned to a combination band [13]. Indeed, the assignment of the very intense gas-phase band at $910 \mathrm{~cm}^{-1}$ to the $\gamma \mathrm{CD}_{3} A^{\prime \prime}$ vibration of both conformers made in Ref. [18] is not consistent with the results of the calculations, as it is not the previous assignment of the $\gamma \mathrm{CD}_{3} A^{\prime}$ vibration of both forms to the $940 \mathrm{~cm}^{-1}$ band (gas phase [18]). This is because the calculated wavenumber difference $\Delta\left(\gamma \mathrm{CD}_{3}\right.$ $\left.A_{\text {trans }}^{\prime}-\gamma \mathrm{CD}_{3} A_{\text {cis }}^{\prime}\right)$ is large $\left(35 \mathrm{~cm}^{-1}\right)$ and thus two bands are expected to appear in the spectrum. (b) The previous [18] assignment of the bands due to the $\delta$ NOC mode in the two conformers is now reversed. Thus, the $333 \mathrm{~cm}^{-1}$ band (gas phase; previously assigned to the cis form [18]) is now 
Table 14

Experimental and MP2 6-311 $\mathrm{G}^{* *}$ calculated isotopic dependence of $\mathrm{ON}=\mathrm{O}$ vibrational wavenumbers of methyl nitrite ${ }^{\mathrm{a}}$

\begin{tabular}{|c|c|c|c|c|c|c|c|c|c|c|c|c|c|}
\hline \multirow[t]{2}{*}{ Species } & & \multirow{2}{*}{\multicolumn{2}{|c|}{$\frac{\nu \mathrm{N}=\mathrm{O}}{\text { Exp. Calc. }}$}} & \multirow[t]{2}{*}{$\Delta \nu^{\exp }$} & \multirow[t]{2}{*}{$\Delta \nu^{\text {calc. }}$} & \multicolumn{2}{|c|}{$\delta \mathrm{O}=\mathrm{N}-\mathrm{O}$} & \multirow[t]{2}{*}{$\Delta \nu^{\exp }$} & \multirow[t]{2}{*}{$\Delta \nu^{\text {calc. }}$} & \multicolumn{2}{|c|}{$\nu \mathrm{N}-\mathrm{O}$} & \multirow[t]{2}{*}{$\Delta \nu^{\exp }$} & \multirow[t]{2}{*}{$\Delta \nu^{\text {calc. }}$} \\
\hline & & & & & & Exp. & Calc. & & & Exp. & alc. & & \\
\hline \multirow{2}{*}{${ }^{12} \mathrm{CH}_{3} \mathrm{O}^{14} \mathrm{NO}$} & Cis & 1613 & 1605 & & & 838 & 881 & & & 625 & 701 & & \\
\hline & Trans & 1665 & 1668 & & & 807 & 854 & & & 565 & 595 & & \\
\hline \multirow[t]{2}{*}{${ }^{13} \mathrm{CH}_{3} \mathrm{O}^{14} \mathrm{NO}$} & Cis & 1611 & 1605 & -2 & 0 & 831 & 873 & -7 & -8 & 625 & 700 & 0 & -1 \\
\hline & Trans & 1667 & 1668 & 2 & 0 & 802 & 850 & -5 & -4 & 560 & 590 & -5 & -5 \\
\hline \multirow[t]{2}{*}{${ }^{12} \mathrm{CH}_{3} \mathrm{O}^{15} \mathrm{NO}$} & Cis & 1586 & 1577 & -27 & -28 & 823 & 864 & -15 & -17 & 621 & 697 & -4 & -4 \\
\hline & Trans & 1639 & 1638 & -26 & -30 & 793 & 839 & -14 & -15 & 560 & 590 & -5 & -5 \\
\hline \multirow[t]{2}{*}{${ }^{12} \mathrm{CD}_{3} \mathrm{O}^{14} \mathrm{NO}$} & Cis & 1616 & 1601 & 3 & -4 & 799 & 838 & -39 & -43 & 596 & 657 & -29 & -44 \\
\hline & Trans & 1667 & 1667 & 2 & 0 & 777 & 813 & -30 & -41 & 552 & 577 & -13 & -18 \\
\hline
\end{tabular}

${ }^{a}$ Wavenumbers in $\mathrm{cm}^{-1}$; experimental data taken from Refs. [12], [13] and [17]; $\Delta \nu$ is the wavenumber shift $\left(\mathrm{cm}^{-1}\right)$ with respect to the corresponding wavenumber in the ${ }^{12} \mathrm{CH}_{3} \mathrm{O}^{14} \mathrm{NO}$ species.

assigned to the $\delta \mathrm{NOC}$ mode in the trans conformer (in addition, this band is also considered to have a partial contribution from the $\tau \mathrm{N}-\mathrm{O}$ mode in the cis form, in agreement with the proximity of the corresponding calculated frequencies of these two modes - 355 and $352 \mathrm{~cm}^{-1}$, respectively). In turn, the $\delta$ NOC mode in the cis conformer is now ascribed to the $304 \mathrm{~cm}^{-1}$ band. Indeed, the calculations clearly show that $\delta$ NOC has a higher wavenumber in the trans than in the cis form, thus justifying the reversal of the previously made assignments [18].

\section{Acknowledgements}

R.F. acknowledges financial support from Junta Nacional de Investigação Científica e Tecnológica, J.N.I.C.T., Lisboa. J.B.P.S., N.B.C.Jr. and M.N.R. acknowledge partial financial support from the Brazilian agencies FACEPE, FINEP and $\mathrm{CNPq}$.

\section{References}

[1] P.J. Tarte, G. Fogarasi, F. Pang and J.E. Boggs, J. Am. Chem. Soc., 101 (1979) 2550.

[2] P. Gray and M.J. Pearson, Trans. Faraday Soc., 59 (1963) 347.

[3] H.W. Brown and D.P. Hollis, J. Mol. Spectrosc., 13 (1964) 305.
[4] P. Klaboe, D. Jones and E.R. Lippincott, Spectrochim. Acta, Part A, 23 (1967) 2957.

[5] P.T. Inglefield, E. Krakower, L.W. Reeves and R. Stewart, Mol. Phys., 15 (1968) 65.

[6] P.H. Turner, M.J. Corkhill and A.P. Cox, J. Phys. Chem., 83 (1979) 1473

[7] P.H. Turner, J. Chem. Soc., Faraday Trans. 2, 2 (1979) 317.

[8] P. Felder and Hs.H. Günthard, Chem. Phys. Lett., 66 (1979) 283

[9] S.H. Bauer and N.S. True, J. Phys. Chem., 84 (1980) 2507.

[10] P.N. Ghosh, A. Bauder and Hs.H. Günthard, Chem. Phys., 53 (1980) 39.

[11] P.N. Ghosh and Hs.H. Günthard, Spectrochim. Acta, Part A, 37 (1981) 347.

[12] P. Felder, T.-K. Ha, A. Dwivedi and Hs.H. Günthard, Spectrochim. Acta, Part A, 37 (1981) 337.

[13] F.L. Rook and M.E. Jacox, J. Mol. Spectrosc., 93 (1982) 101.

[14] J.P. Chauvel, Jr. and N.S. True, J. Phys. Chem., 87 (1983) 1622.

[15] C.B. Conboy, J.P. Chauvel, Jr., P.P. Moreno, N.S. True and C.M. Ott, J. Phys. Chem., 90 (1986) 4353.

[16] B.J. van der Veken and R. Maas, J. Mol. Struct. (Theochem), 200 (1989) 413.

[17] M. Bodenbinder, S.E. Ulic and H. Willner, J. Phys. Chem., 98 (1994) 6441

[18] H.T. Stidham, G.A. Guirguis, B.J. van der Veken, T.G. Sheehan and J.R. Durig, J. Raman Spectrosc., 21 (1990) 615 .

[19] B.J. van der Veken, R. Maas, G.A. Guirguis, H.T. Stidham, T.G. Sheehan and J.R. Durig, J. Phys. Chem., 94 (1990) 4029.

[20] F.R. Cordell, J.E. Boggs and A. Skancke, J. Mol. Struct., 64 (1980) 57.

[21] P. Pulay, G. Fogarasi, F. Pang and J.E. Boggs, J. Am. Chem. Soc., 101 (1979) 2550 
[22] G.E.P. Box, W.G. Hunter and J.S. Hunter, Statistics for Experimenters, Wiley, New York, 1978.

[23] M.S. Gordon, Chem. Phys. Lett., 163 (1980) 76.

[24] R. Krishnan, J.S. Binkley, R. Seeger and J.A. Pople, J. Chem. Phys., 192 (1980) 690.

[25] M.J. Frisch, J.A. Pople and J.S. Binkley, J. Chem. Phys., 80 (1984) 3265.

[26] M.J. Frisch, G.W. Trucks, M. Head-Gordon, P.M.W. Gill, M.W. Wong, J.B. Foresman, B.J. Johnson, H.B. Schlegel, M.A. Robb, E.S. Replogle, R. Gomperts, J.L. Andres, K. Raghavachari, J.S. Binkley, C. Gonzalez, R.L. Martin, D.J. Fox, D.J. DeFrees, J. Baker, J.J.P. Stewart and J.A. Pople, Gaussian 92, Revision C, Gaussian Inc., Pittsburgh, PA, 1992.

[27] H.B. Schlegel, Ph.D. Thesis, Queen's University, Kingston, Ont., Canada, 1975.

[28] M.D.G. Faria and R. Fausto, TRAnsFormer (version 1.0), Departamento de Química, Universidade de Coimbra, Portugal, 1990.

[29] M.D.G. Faria and R. Fausto, BUILD-g and vibrat, Departamento de Quimica, Universidade de Coimbra, Portugal,
1990. (These programs incorporate several routines from programs GMAT and FPERT, H. Fuher, V.B. Kartha, K.G. Kidd, P.J. Krueger and H.H. Mantsch, Natl. Res. Council Can. Bull., 15 (1976) 1.)

[30] I.S. Scarminio and R.E. Bruns, Trends Anal. Chem., 8 (1989) 326.

[31] Ein*Sight Pattern Recognition Software (Version 3.0), Infometrix Inc., 2200 6th Av., Suite 833, Seattle, WA 98121, 1991.

[32] M.J. Corkill, A.P. Cox and P.H. Turner, 7th Austin Symp. on Molecular Structure, Austin, TX, 1978, Paper TA6.

[33] R.M. Lees and J.G. Baker, J. Chem. Phys., 30 (1968) 5299.

[34] K. Tomagawa, M. Takemura, S. Konaka and M. Kimura, J. Mol. Struct., 125 (1984) 131.

[35] J.J.C. Teixeira-Dias and R. Fausto, J. Mol. Struct., 133 (1986) 199.

[36] K.V. Mavdia, J.T. Kent and J.M. Bibby, Multivariate Analysis, Academic Press, London, Chapter 8, 1979.

[37] E. Suto, M.M.C. Ferreira and R.E. Bruns, J. Comput Chem., 12 (1991) 885. 